\title{
Assessment of the adequacy of mobile applications for disaster reduction
}

\author{
Lucía Navarro de Corcuera ${ }^{1}$ (D) - María del Mar Barbero-Barrera ${ }^{2}$ (D) . \\ Ana Campos Hidalgo ${ }^{3}$. Jorge Recio Martínez ${ }^{4}$
}

Received: 27 August 2020 / Accepted: 25 July 2021 / Published online: 6 September 2021

(c) The Author(s) 2021

\begin{abstract}
Natural events continue to take a heavy toll on human lives. Added to this are the challenge of dynamic at-risk settings, uncertainty, and increasing threats, which demand holistic, flexible, and quickly adaptable solutions. In this context, mobile applications are strongly emerging as communication tools that can assist in disaster reduction. Yet, these have not been sufficiently evaluated. In view of this, the aim of this research is to evaluate the adequacy of mobile applications in disaster risk reduction in reference to some of the deadliest natural events. To this purpose, a two-part methodology is developed. Firstly, a random sample of applications is evaluated and contrasted with the literature. Secondly, the viability of mobile applications is determined based on the Digital Application Potential Index proposed by the authors, cross-referenced in Geographical Information Systems with the WorldRiskIndex. The results show that most mobile applications limit their coverage range to only one stage of Disaster Risk Management (DRM) and one type of hazard event, failing to address systemic risk and hampering the scale-up of humanitarian response. For these to become adequate and wide-reaching, strong policies to promote reliability, transparency, and citizen empowerment would be required. The policies establishing the use of mobile applications as a viable tool for DRM must consider reducing the prices of internet connectivity while increasing educational levels, on top of language translation. At this point, the adoption of mobile applications is unable to ensure DRM communication,
\end{abstract}

María del Mar Barbero-Barrera

mar.barbero@upm.es

Lucía Navarro de Corcuera

lucia.navarro@decorcuera.com

Ana Campos Hidalgo

ana.campos.hidalgo@alumnos.upm.es

Jorge Recio Martínez

jorge.recio.martinez@alumnos.upm.es

1 ICHaB-ETSAM. ETSAM, Arcoíris NGO, Universidad Politécnica de Madrid, Avenida Juan de Herrera 4, 28040 Madrid, Spain

2 Department Construction and Technology in Architecture. ICHaB-ETSAM. ETSAM, Universidad Politécnica de Madrid, Avenida Juan de Herrera 4, 28040 Madrid, Spain

3 Universidad Politécnica de Madrid, Avenida Juan de Herrera 4, 28040 Madrid, Spain

4 Universidad Politécnica de Madrid (Spain), Avenida Juan de Herrera 4, 28040 Madrid, Spain 
especially in countries with higher-risk levels, requiring these to be complemented with auxiliary tools.

\section{Graphic abstract}

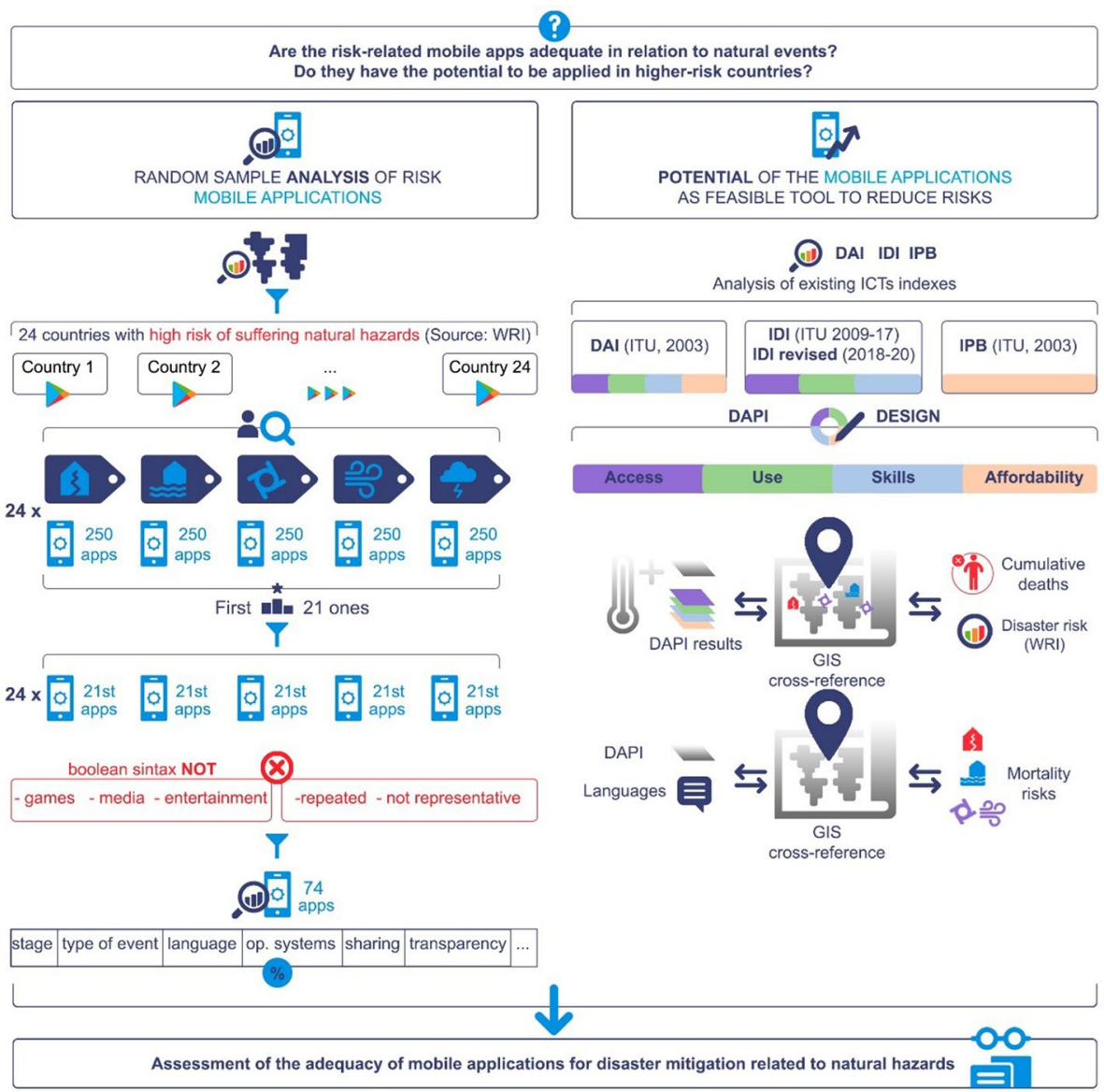

Keywords Disaster Risk Management - Information and Communication Technologies · Mobile applications $\cdot$ Natural hazards

\section{Introduction}

A preliminary note on terminology: It is important to understand that the authors have intentionally avoided using the term natural disasters. Despite its colloquial use, it is incorrect. A natural event becomes a disaster when multiple factors converge that are not natural at all (World Bank \& United Nations, 2010). Therefore, instead of 'natural' disasters, we will refer to disasters related to natural events. 


\subsection{Disasters associated with natural hazards}

According to the 2020 risk report, extreme weather events and disasters associated with natural hazards are in the top three long-term global risks in terms of likelihood for the third consecutive year (WEF, 2020). These are amplified by the emergence of growing inequality amidst socio-natural situations, climate change, and climate action failure (CRED \& USAID, 2020; Evans, 2019; Guha-Sapir et al., 2015; UNDRR, 2019). The number of deaths worldwide due to natural events is highly variable from year to year, averaging about 60,500 people in the last 25 years (pre-COVID-19 data). However, when taking injured, affected, and homeless into account, this amount rises to 5 billion (CRED \& USAID, 2020; Guha-Sapir et al., 2015), to which about 24 million annual migrants must be added (UNDRR, 2019).

The most deadly natural hazards between 1995 and 2020 (CRED \& USAID, 2020; Guha-Sapir et al., 2015) were earthquakes, cyclones, and floods. Earthquakes caused more than 760,000 deaths ( $49 \%$ of total deaths), followed by storms (including hurricanes, cyclones, and storm surges) with more than 250,000 fatalities (16\% of total deaths, of which cyclones accounted for $15 \%$ ). Finally, floods had the farthest reaching impact, affecting 2.5 billion people (Table 1) and resulting in $11 \%$ of total deaths (over 170,000 people).

The cumulative number of deaths between 1995 and 2020 is graphically displayed in Fig. 1, following a light-to-dark scale according to severity. As can be observed, floods are the most widespread climate event, highlighting climate change effects (Chang \& Franczyk, 2008; Economy, 2018), while storms are the most deadly natural phenomenon (Wahlstrom \& Guha-Sapir, 2015), with a higher prevalence in Eastern Asia. The latter is also an

Table 1 Number of events, deaths (including missing people), and affected people (sum of injured, affected, and homeless) by type of natural event from 1995 to 2020

\begin{tabular}{|c|c|c|c|c|c|c|}
\hline TYPE & DEATHS & $\begin{array}{c}\% \\
\text { DEATHS }\end{array}$ & AFFECTED & $\begin{array}{c}\% \\
\text { AFFECTED }\end{array}$ & $\begin{array}{r}\text { EVENT } \\
\mathrm{S}\end{array}$ & $\begin{array}{c}\% \\
\text { EVENTS }\end{array}$ \\
\hline EARTHQUAKES & 764,278 & 48.5 & $137,373,596$ & 2.6 & 681 & 6.8 \\
\hline STORMS & 251,895 & 16.0 & $852,633,977$ & 16.4 & 2,515 & 25.2 \\
\hline CYCLONES & 236,613 & 15.0 & $559,475,829$ & 10.8 & 1,410 & 14.1 \\
\hline OTHER STORMS & 15,282 & 1.0 & $293,158,148$ & 5.6 & 1,105 & 11.1 \\
\hline FLOODS & 174,945 & 11.1 & $2,514,925,985$ & 48.4 & 3,802 & 38.0 \\
\hline Extreme temperature & 172,600 & 11.0 & $98,469,317$ & 1.9 & 484 & 4.8 \\
\hline Epidemic & 162,065 & 10.3 & $13,679,924$ & 0.3 & 1,141 & 11.4 \\
\hline Landslide & 23,036 & 1.5 & $6,340,096$ & 0.1 & 477 & 4.8 \\
\hline Drought & 22,380 & 1.4 & $1,562,805,180$ & 30.1 & 411 & 4.1 \\
\hline Wildfire & 2,064 & 0.1 & $3,491,120$ & 0.1 & 307 & 3.1 \\
\hline Volcanic activity & 1,657 & 0.1 & $5,577,411$ & 0.1 & 126 & 1.3 \\
\hline Mass movement (dry) & 382 & 0.0 & 4,285 & 0.0 & 13 & 0.1 \\
\hline Animal accident & 12 & 0.0 & 5 & 0.0 & 1 & 0.0 \\
\hline Insect infestation & & 0.0 & $2,800,200$ & 0.1 & 35 & 0.4 \\
\hline Impact & & 0.0 & 301,491 & 0.0 & 1 & 0.0 \\
\hline $\begin{array}{l}\text { ALL NATURAL } \\
\text { EVENTS }\end{array}$ & $1,575,314$ & & $5,198,402,587$ & & 9,994 & \\
\hline
\end{tabular}

Calculations from (CRED \& USAID, 2020; Guha-Sapir et al., 2015) 


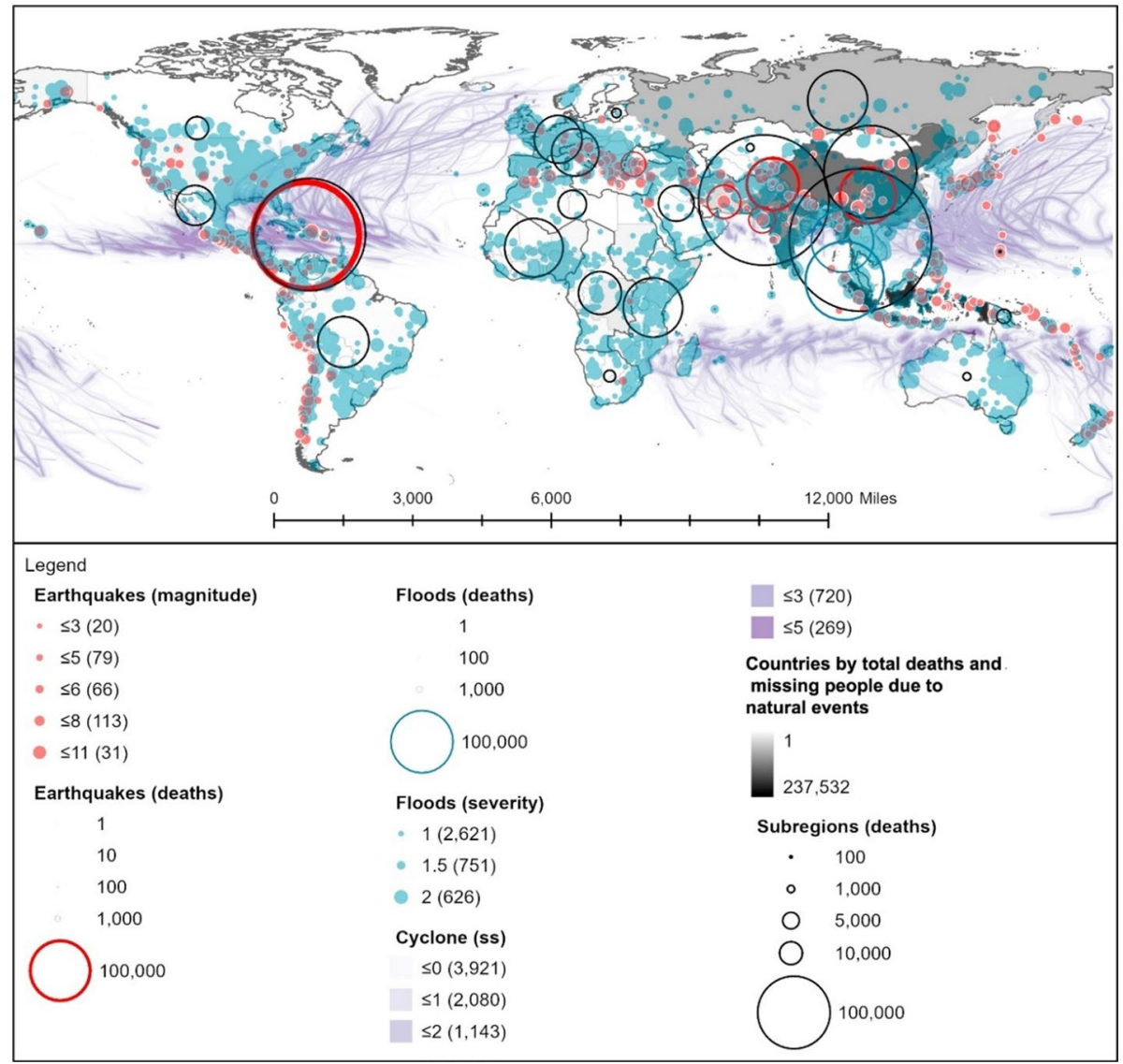

Fig. 1 Location, intensity, and deaths linked to historical floods, earthquakes, and cyclones, based on: flooding events by severity (Severity Classification according to the Dartmouth Flood Observatory (DFO). The assessment is conducted on a scale from 1 to 2 . Floods are then divided into three classes. Class 1 : large flood events: significant damage to structures or agriculture; fatalities; and, or 1 to 2 decades-long reported intervals from previous similar event. Class 1.5: very large events: estimated recurrence interval composed of 20 to 100 years, and, or a local recurrence interval of 1 to 2 decades that affects a large geographic region $(>5000 \mathrm{~km} 2)$. Class 2: Extreme events: with an estimated recurrence interval of more than 100 years) and deaths (Brakenridge, n.d.; Dartmouth Flood Observatory, 2020); major earthquakes (with magnitudes higher than 5.0) by magnitude and deaths by ANSS (ANSS-Advanced National Seismic System, 2020). Conversion to shapefile in ArcGIS and extraction of the 1995-2000 period; tropical cyclones windspeed buffers according to the Saffir-Simpson category scale. UNEP/DEWA/GRID-Europe (Global Risk Data Platform, 2020). Extraction of the 1995-2000 period; shapefile countries: Esri, Garmin, CIA World Factbook (References:: Regional and World Maps-The World Factbook-Central Intelligence Agency, 2020). The deaths and missing persons attributed to disasters were linked by country ISO code from the Emergency Events Database (EM-DAT); the subregional and regional shapefile and data were created by dissolving countries according to the region codes in the Standard country or area codes for statistical use (M49) and based on the United Nations Development Programme Statistical Division (Regional Groupings-SDG Indicators, 2020). The sum of total deaths registered by country ISO code EM-DAT was added to the shapefile 
earthquake-prone area, together with the West coast of America, which exhibits the leading number of deaths. ${ }^{1}$

\subsection{A systemic and complexity approach to disaster risk management (DRM): flexible and quick strategies}

The concept of risk is intertwined with that of systemic epistemology, in that it entails a multi-dimensional perspective, scale, and impact (UNDRR, 2019). A hazard turns into a disaster when the magnitude and impact of the event lead to vulnerable states, where the capacity of subjects to cope with the event (resilience) and to repair what has been damaged and reconstruct itself (self-poiesis) (Cardona Arboleda, 2008) has been compromised. The relationship between complexity and risk, together with social and environmental aspects, emerges from the global framework for DRM (UNDRR, 1994), which includes prevention, mitigation, and preparedness (UN, 2015; Wahlstrom \& Guha-Sapir, 2015). To achieve a comprehensive DRM, five main steps are considered at all stages (Fig. 2): 1. prevention; 2. mitigation; 3. preparedness; 4. response; 5. recovery (Arce et al., 2012; Coppola, 2011; Uitto \& Shaw, 2016). ${ }^{2}$

To address the complexity of risk, including change and uncertainty, the challenge lies in designing holistic, flexible, and effective plans, as well as strategies that set the path for a quick response and the ability to adapt solutions in real time (UNDRR, 2019). For this purpose, clear communication is essential at all stages of DRM (Giroux et al., 2009; Victor, 2014). In fact, the effectiveness and quality of communication with the local population,

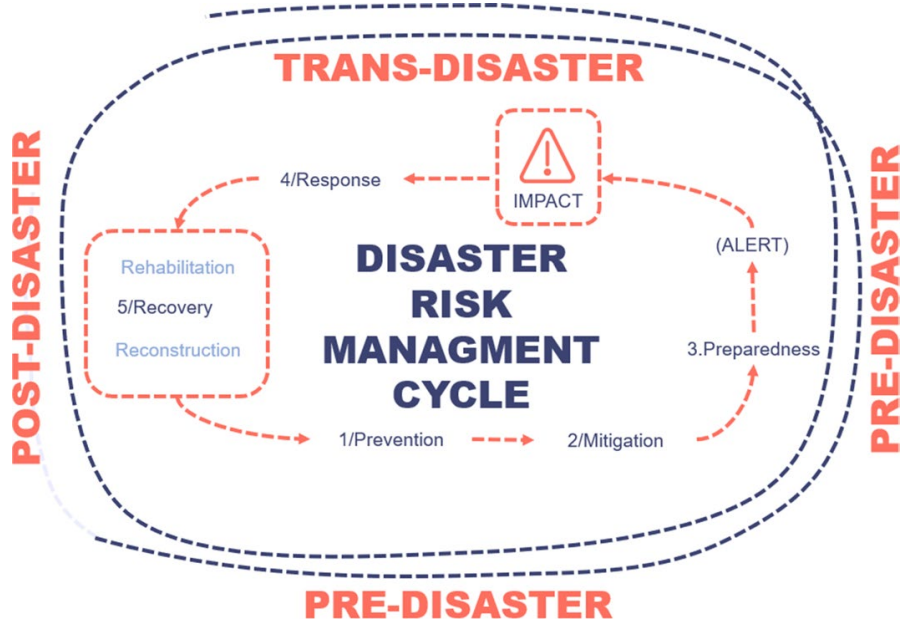

Fig. 2 DRM Stages. Preparedness by the authors and adapted from (Arce et al., 2012; Coppola, 2011; Foresti, 2015; Ludwig \& MATTEDI, 2018; Uitto \& Shaw, 2016)

\footnotetext{
1 The deaths by cyclones are not displayed since they are not georeferenced in the international database, as happens with those stemming from floods and earthquakes.

2 The five components are arranged in a circular-spiral model of DRM approach. This facilitates the understanding of disasters as integrated processes in which the stages that occur in the pre-disaster period are linked to those of the post-disaster period. The spiral feature of the model highlights the upgrade in resilience with each passing cycle (Foresti, 2015; Ludwig \& MATTEDI, 2018).
} 
before and after the phenomena, is a key point for mitigating disasters related to natural hazards.

\subsection{Are Information and Communication Technologies (ICTs) the solution for DRM?}

Technological tools could constitute an alternative to facilitate efficient and rapid communication (Verrucci et al., 2016), as these have become increasingly widespread among the population. Mobiles, in particular, would be a viable tool, considering that about $70 \%$ of the global population is projected to be subscribed to mobile services (about 5.8 billion people) in 2025 (Association, 2020) and that most of the world's population lives within reach of a mobile cellular signal (97\%) (ICT et al., 2019).

In the last decade, research on the potential of ICTs in DRM has been carried out (Cioca et al., 2009; Ludwig \& MATTEDI, 2018; Reddick, 2011; Wang et al., 2016), covering a wide range of uses, such as SMS (Cioca et al., 2009; Homier et al., 2018), television broadcast (Grassau et al., 2019; Segura et al., 2015; Wahyu et al., 2012), radio (Cardoso et al., 2014), social network (Doktor \& Giroux, 2011; Dunn Cavelty \& Giroux, 2011; Norris, 2017; Peterson et al., 2019; Rogstadius et al., 2011), e.g. Twitter (Hong et al., 2017; Layek et al., 2018; Peterson et al., 2019), as well as digital applications (Bachmann et al., 2015; Park, 2017; Verrucci et al., 2016), and the internet (Bachmann et al., 2015; Webb et al., 2010). Other ICTs that are proving to be relevant to all phases of DRM are the development of geographical information systems (GIS) (Hongbo et al., 2014) and remote sensing (Sausen \& Lacruz, 2015; Troy et al., 2008). It is also interesting to consider the contributions of the Internet of Things applied to evacuation plans (Xu et al., 2018), early warning systems, and risk monitoring (Arshad et al., 2019).

Despite the clear potential of the ICTs, there is previous research pointing to the drawbacks and threats linked to their use. For starters, the role played by the predisposition of individuals in guaranteeing effective information transmission should be considered (Karanci et al., 2005). Furthermore, there is the danger of infiltration of harmful information in bidirectional systems (Giroux et al., 2013; Lindsay, 2011), which could be reduced by setting up an Information Management Team (Homier et al., 2018). What is more, the current world's population does not benefit from a full mobile network and internet coverage, particularly when it comes to the most vulnerable population.

In spite of these shortcomings, the use of technology could enhance the speed of dissemination of information (Johnson, 1998) and mitigate the effects of disasters on the population (Palen et al., 2007; Shklovski et al., 2010). Moreover, the issue of electricity access and possible power outages during an active disaster scenario should also be taken into consideration. Possible solutions for this could lie in working offline and relying on automated backup options (Lindsay, 2011; UNDRR, 2019). An ever-expanding number of digital applications have been developed in this regard and require systematic reviews (Bachmann et al., 2015).

\subsection{The aim: evaluating the adequacy of mobile applications for reducing the adverse effects of natural hazards}

Risks linked to natural hazards are subjected to change, uncertainty, and growing threats and hence require flexible solutions that can adapt on a real-time basis. At the same time, there is a proliferation of digital applications (apps) with great potential for reducing the adverse effects of natural hazards, in that they would improve communication at all stages 
of DRM (pre- and post-event). Yet, few studies have assessed this potential, all the more so if the parameters of risk exposure and vulnerability of each country are taken into consideration. In view of this, this research aims to assess the adequacy and viability of mobile apps worldwide for disaster risk reduction, linked to some of the current deadliest natural hazards, i.e. earthquakes, cyclones, and floods. Are existing disaster-related mobile apps used so far in the deadliest natural events adequate? Do they have the potential to be applied in high-risk countries?

\section{Materials and methods}

To answer these questions a two-part methodology (Fig. 2) was developed. First off, an analysis of a random sample of the risk-related mobile apps available in high-risk countries was performed to extract conclusions about their adequacy, covering their characteristics and comparing them with the existing literature.

Moreover, an appraisal of the potential of mobile apps (according to their access, use, affordability, and skills) was conducted per country, using the indicator proposed by the authors: the DAPI (Digital Application Potential Index). The DAPI and each of its components were cross-referenced in GIS with the disaster risk of each country provided in the existing WorldRiskIndex (WRI), as well as with each selected hazard (hurricanes, earthquakes, and floods) and cumulative deaths by subregion. Each analysis is illustrated via visual maps to facilitate its understanding (Fig. 3).

\subsection{Random sample analysis of risk-related mobile applications available in high-risk countries}

In order to make the research feasible, the scope of the sample for a preliminary analysis was limited to 24 countries across the world, based on their high risk of exposure according to the WRI 2019 (Mucke, 2019). The search was performed by region and country, mainly with the Android OS in mind, since $74.14 \%$ of smartphones currently use it as an operating system (Stats, 2019). In addition, the Google Play Store application was the main search engine, due to being available in most phones.

The Google Play Store does not arrange the applications associated with natural hazards in a single category (Google, 2020), and there is no global consensus among developers in terms of indexing and search tags, which also applies to natural hazard applications (Strzelecki, 2019). Hence, five keywords related to the deadliest natural hazards were determined: "Earthquake", "Flood", "Hurricane", "Cyclone", and "Storm". The keywords were translated into each country's official languages, and the search was carried out in the Play Store of each respective country. Following this procedure, the Play Store displayed a maximum of 250 applications per keyword search and country, returning a first sample of $30,000(250 \times 5 \times 24)$. The first twenty-one results per keyword were selected. Their order of appearance relies on a ranking system based on user ratings, downloads, and other internal criteria of the search engine (Karagkiozidou et al., 2019). The Google algorithm presents limitations related to the display order of the applications, which depends on geolocation, navigation preferences, and type of smartphone, to name a few.

Afterwards, an advanced search was performed using Boolean operators. The terms "-games", "-media", and "-entertainment" were applied to exclude off-topic games and 


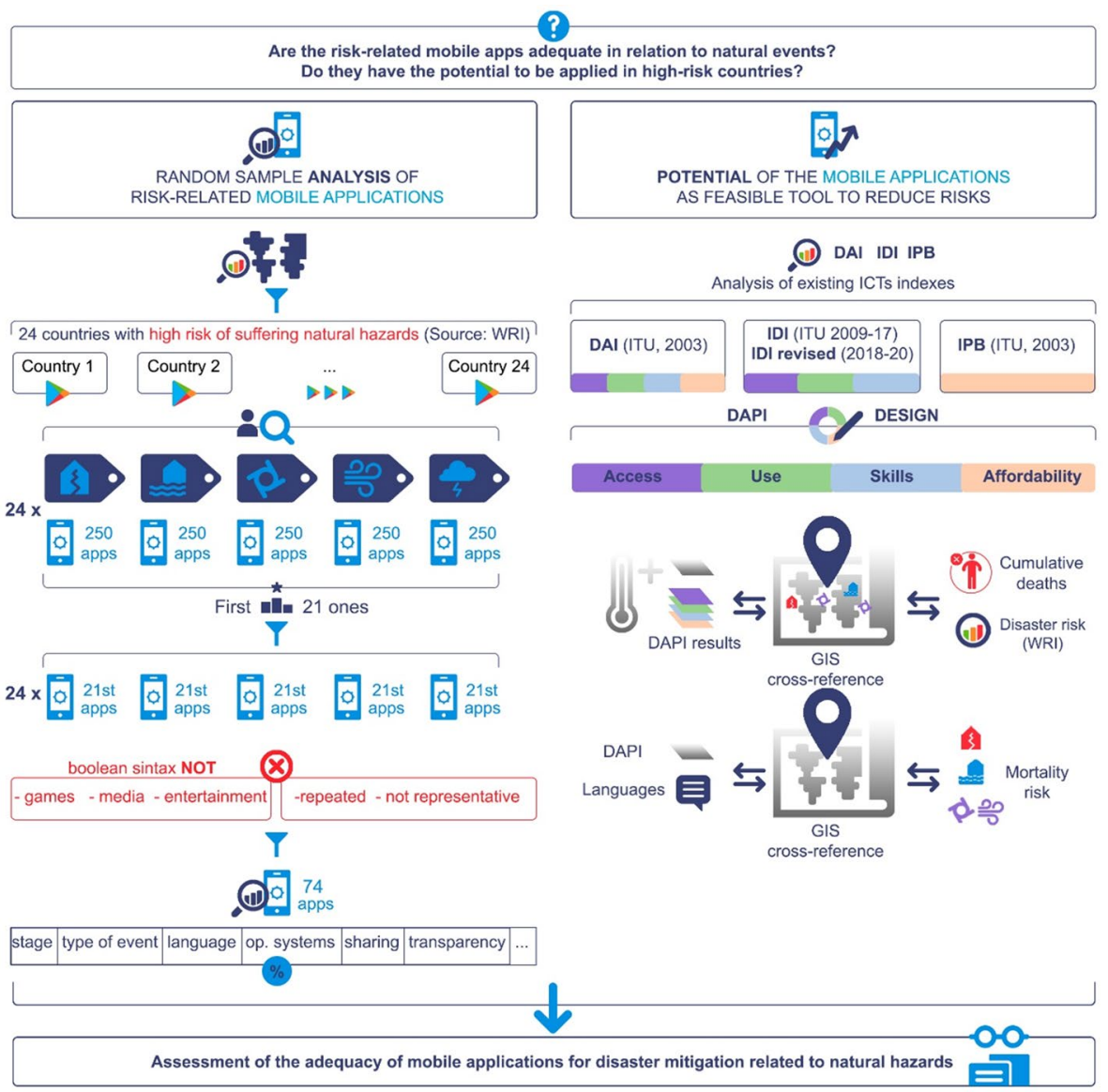

Fig. 3 Research methodology flow

apps, thus narrowing down the results and improving accuracy. Finally, unrepresentative or repeated apps were manually discarded, resulting in a final selection of 73 mobile apps.

The latter was classified into two DRM stages: pre-disaster and trans-post-disaster. To obtain an overview of these applications and evaluate them, a few useful parameters were collected, such as the compatibility with Android or IOS operating system, language options, and the possibility of sharing warning messages on social networks. The transparency and reliability of each application were assessed through the identification of the type of developer, the clarity of given and received information, and who has access to it. These aspects are relevant to ensure the confidential treatment of the data, prevent their alteration or access for advertising purposes, as well as an efficient coordination at the institutional level. 


\subsection{Evaluation of the risk reduction potential of mobile applications}

Over the years the International Telecommunication Union (ITU) has developed several indicators related to the potential of ICTs, most of them in reference to technology accessibility in general. Of particular interest to the research is the Digital Access Index (ITU, 2003), which measures the overall ability of individuals in a country to access and use ICTs. It is composed of five categories (infrastructure, affordability, knowledge, quality, and usage) and eight indicators. In 2009 they created the ICT Development Index (IDI) to assess and benchmark developments in ICTs. The original IDI was updated every year till 2017 (ITU, 2017). Compared to the Digital Access Index, the IDI redistributes quality in access and use categories, while discarding affordability (Table 2).

In response to technological developments, a revised ICT Development Index has been updated every year (ITU, 2019, 2018, 2020), adding more indicators. However, according to the ITU Secretariat, the revised IDI indicates that the methodology developed for the new indicators lacks robustness. For affordability, the ITU created a specific indicator: the ICT Price Basket 2019. This index measures ICTs' relative price (fixed telephone, mobile cellular, and fixed broadband) as a percentage of gross national income per capita (GNI p.c.) (ICT et al., 2019).

On the basis of these previous indicators, the authors put forth a new composite indicator conforming to the purposes of the research, i.e. the Digital Application Potential Index (DAPI). The latter stems from the combination of the 2003 Digital Access Index, which includes affordability among its components, and the 2017 ICT Development Index. Affordability is a key parameter for evaluating the adequacy of mobile apps as a tool for risk management, as these must be accessible to the most vulnerable, and thus, the parameter of affordability was included with the most updated ICT Price Basket database. It must be pointed out that only the most accessible option for vulnerable users was used, i.e. the cheapest mobile service with data option (data and voice low consumption) from the indicators in the ICT Price Basket. Since the scope of the research only includes the evaluation of mobile apps, the fields indicated in red (Table 2) regarding computers, fixed telephone,

Table 2 Comparative table of the Digital Access Index (ITU, 2003) and ICT Development Index by ITU (ITU, 2017)
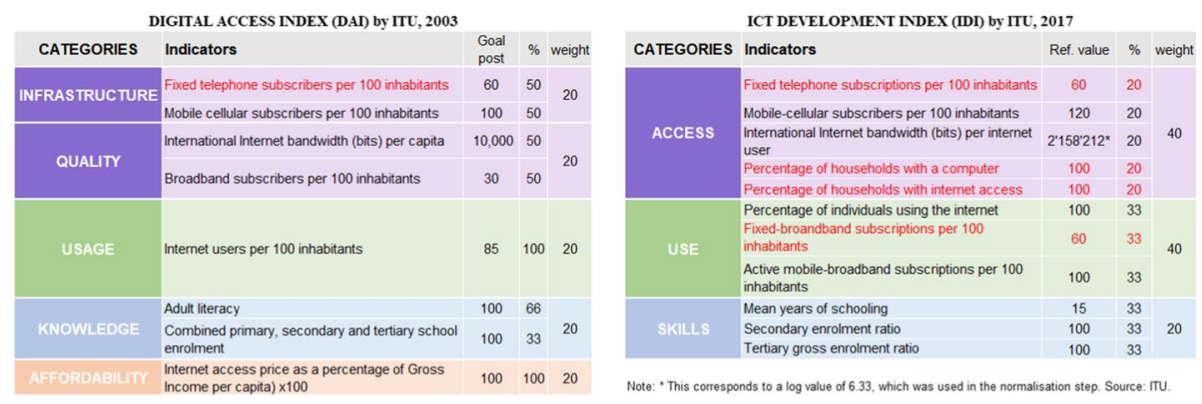

The indicators and categories have been rearranged to facilitate the comparison among similar items 
Table 3 Description of the categories and indicators considered in the development of the Digital Application Potential index (DAPI).

\begin{tabular}{|c|c|c|c|c|c|}
\hline \multicolumn{6}{|c|}{ DAPI index } \\
\hline CATEGORIES & Indicators & ref. value & $\%$ & weight & SOURCE \\
\hline \multirow{4}{*}{ ACCESS } & Access to a mobile phone ( $\%$ age $15 t)$ & 100 & 25 & \multirow{4}{*}{30} & World Bank Global Findex database \\
\hline & $\begin{array}{l}\text { International Internet bandwidth (kb/s) per } \\
\text { internet user. (Normalised). }\end{array}$ & $1024 \mathrm{~Kb} / \mathrm{s}^{*}$ & 25 & & $\begin{array}{l}\text { WTCdata } 360 \text { World Bank Data, from WEF - } \\
\text { Global Information Tech. Last data available } \\
\text { between } 2014-2016 \text {. }\end{array}$ \\
\hline & Mobile network coverage (\% population) & 100 & 25 & & $\begin{array}{l}\text { TCdata } 360 \text { World Bank Data, from WEF - Global } \\
\text { Information Tech. Last data available between } \\
2015-2016 \text {. }\end{array}$ \\
\hline & Access to electricity & 100 & 25 & & $\begin{array}{l}\text { United Nations Development Programme. } \\
\text { Human Development Data (1990-2018) }\end{array}$ \\
\hline \multirow[b]{2}{*}{ USE } & $\begin{array}{l}\text { Percentage of individuals using the } \\
\text { internet }\end{array}$ & 100 & 50 & \multirow[b]{2}{*}{30} & $\begin{array}{l}\text { United Nations Development Programme. } \\
\text { Human Development Data (1990-2018) }\end{array}$ \\
\hline & $\begin{array}{l}\text { Active mobile-broadband subscriptions } \\
\text { per } 100 \text { inhabitants }\end{array}$ & 100 & 50 & & $\begin{array}{l}\text { TCdata360 World Bank Data, from ITU } \\
\text { Database. Data } 2015 .\end{array}$ \\
\hline \multirow{3}{*}{ SKILLS } & Adult literacy rate & 100 & 33 & \multirow{3}{*}{20} & $\begin{array}{l}\text { United Nations Development Programme. } \\
\text { Human Development Data (1990-2018) }\end{array}$ \\
\hline & Secondary gross enrolment ratio & 100 & 33 & & $\begin{array}{l}\text { United Nations Development Programme. } \\
\text { Human Development Data (1990-2018) }\end{array}$ \\
\hline & Tertiary gross enrolment ratio & 100 & 33 & & $\begin{array}{l}\text { United Nations Development Programme. } \\
\text { Human Development Data (1990-2018) }\end{array}$ \\
\hline AFFORDABILITY & $\begin{array}{l}\text { ICT Price Basket (IPB) } \\
\text { Low-usage data and voice basket with a } \\
\text { monthly allowance of } 70 \text { minutes, } 20 \text { SMS } \\
\text { and } 500 \mathrm{MB} \text {. \% of GNI p.C. }\end{array}$ & $100-$ & 100 & 20 & $\begin{array}{l}\text { ITU 2019. Measuring Digital Development. ICT } \\
\text { Price Trends } 2019\end{array}$ \\
\hline
\end{tabular}

Note: * $4 \mathrm{Mb} / \mathrm{s}$ is the minimum considered for basic applications such as sending mail and browsing (Saunders et all 2012). 1Mb/s is $1024 \mathrm{~kb} / \mathrm{s}$

and internet at home were excluded. Table 3 describes the final categories and indicators and all the source databases used for calculations in the development of the DAPI. ${ }^{3}$

To discuss the potential of digital apps in risk reduction in different countries, as well as the measures for rendering them usable, the DAPI and its components were cross-referenced in GIS with the disaster risk of each country listed in the existing WRI (Mucke, 2019). The WRI establishes the relationship between the exposure to natural events and the vulnerability of each country. All these values were added as fields in each country through GIS and displayed in maps. To facilitate the discussion of findings, the DAPI results were divided into quintiles, following a visual criterion according to which the darker the colour of the country in the map, the less viable will mobile apps be. In addition, for each component of the DAPI, the values were averaged, and the countries were grouped by risk category. The maximum and minimum values were included in a tabulated form to discuss the range of variability.

\section{Results and discussion}

\subsection{General overview of mobile apps}

Nowadays, mobile apps have become an additional tool of communication on top of traditional ones, such as television or radio (Lindsay, 2011; Wahyu et al., 2012). However, it must be highlighted that this type of apps should not depend exclusively on mobile data,

${ }^{3}$ When missing data, the following adjustments were made for the calculations:

- when an indicator's component value was unavailable for a specific country, the weight was redistributed among the remaining components;

- the access was not computed if two indicators were not available;

- the overall DAPI value was only obtained when all four components were present. 
so as to guarantee the highest percentage of population coverage inclusive of users that lack mobile data access or in the event of facing network failure. Social networks (Hong et al., 2017; Peterson et al., 2019) and SMS (Cioca et al., 2009; Webb et al., 2010) are among the most common alternatives to mobile apps. These media have proven to be beneficial not only for mitigation purposes and accessing a large number of the population, but also to re-establish communication between people and within the community (Shklovski et al., 2010), to create collaborative maps (Doktor \& Giroux, 2011; Dunn Cavelty \& Giroux, 2011; Layek et al., 2018), to extend the management capacity of safeguard services, and to prioritise actions that could have been disregarded by public services (Giroux et al., 2013; Norris, 2017; Palen et al., 2007; Wang et al., 2016). Nonetheless, only $28 \%$ and $36 \%$ of the applications assessed in this research permitted information sharing through other social networks or SMS in both phases: pre- and post-trans disaster, respectively, which is significantly low. Moreover, globally only $30 \%$ allowed information (photographs, videos, and reports) to be shared, which can be very useful for determining the extent of damage to the territory. The addition of other features in information sharing, such as collaborative maps, would be of great interest.

Another striking finding was the importance of interconnecting all phases and disaster types to improve the effectiveness of the humanitarian response (Park, 2017) and ergo offer advice and warnings tailored to each area, along with the scale and type of disaster. Notwithstanding this, only $10 \%$ of digital applications analysed presently cover both preand trans-post-disaster phases (7 apps), in contrast to the $77 \%$ focussing on the pre-disaster phase and the $14 \%$ centred on the trans-post-phase. Additionally, the pre-disaster approach seemed rather insufficient, solely depending on warnings and advice on how to proceed against risks. On the other hand, the trans-post-disaster apps, included those intended to collect information, mostly focussed on locating citizens (75\%).

Furthermore, most mobile apps limit their coverage to a single type of natural event (78\% of the sample), so multi-hazard applications should be promoted (Verrucci et al., 2016) for resource optimisation and efficient stakeholder coordination.

What is more, public entities could provide information about public facilities that cover basic needs, such as water and food, healthcare facilities, and shelter locations, apart from providing safeguard emergency services (Park, 2017). From this point of view, the use of a single application would optimise and accelerate response management (Park, 2017; Verrucci et al., 2016) and could strengthen local capacities among regions for disaster preparedness. Moreover, using artificial neural networks (Pashazadeh \& Javan, 2020) and artificial intelligence (Abarca-Alvarez et al., 2019) for building forecasting models (Ogania et al., 2019; Williams \& Lück-Vogel, 2020) could have a beneficial impact, and it could be adequately complemented by spatial-temporal detection systems (Yu et al., 2020) and the Internet of Things (Arshad et al., 2019; Xu et al., 2018).

In addition, a team of specially trained professionals must be responsible for the DRM communication to secure its effectiveness (Homier et al., 2018), as happens with the Red Cross and the Surge Information Management Support. This team is of great importance to empathically transmit collective recommendations and specific messages at a time of social pressure (Giroux et al., 2013; Grassau et al., 2019; Hong et al., 2017). Per contra, the latter can exercise control over the news delivered as well as over users with malicious intent (Giroux et al., 2013). According to previous research, this specialised training should be extended to local leaders to ensure the effectiveness of the preparedness actions (Verrucci et al., 2016).

However, the strategy laid out above clashes with the fact that $55 \%$ and $79 \%$ of the preand trans-post-disaster applications, respectively, were found to be developed by private 
companies. The high rate of app development in the private sector stems from strategic and market exploration agreements, perceiving social issues to be new investment opportunities. More often than not, the information collected may be used for statistical and marketing purposes without the users' knowledge or consent (Kemper \& Kolkman, 2019). Due to weak data protection and privacy legislation, the "datification" in medium- and lowincome countries with high levels of risk and vulnerability could lead to unwanted scenarios of information monopolisation by the private sector (Roth \& Luczak-Roesch, 2020). To prevent the misuse or abuse of citizen information collected by third parties, government agencies and academic institutions created protocols such as Open Data, FAIR data (Findable, Accessible, Interoperable, Reusable) (Wilkinson et al., 2016), and FACT data (Fairness, Accuracy, Confidentiality, and Transparency) (Van der Aalst et al., 2017). These promote the need for policies that endorse reliability, transparency, citizen empowerment and control over their data, in a way that does not hinder private development, preserves citizens' rights, and assures availability for researchers and organisations. A strong public service can protect the population from private interest while enforcing information reliability together with leading management transparency.

\subsection{Evaluation of the adequacy of the mobile applications}

From a general point of view, a trend was identified in which the lower the disaster risk, the higher the potential of using mobile apps (DAPI value) (Table 4). This statement is true when considering the minimum DAPI values, yet some discrepancies were observed in regard to the maximum DAPI values for low and high disaster risk categories, as well as regarding mean DAPI values. This is due to the extremely wide range of values among countries within the same risk category. This evidences that, to date, mobile apps cannot be used as the sole communication tool in countries with high levels of disaster risk.

\subsubsection{Access component of the DAPI and risk}

Four indicators were considered for the evaluation of the access component: mobile phone access, expressed as the percentage of population over 15 years old; international internet bandwidth $(\mathrm{kb} / \mathrm{s})$ per internet user (normalised); mobile network coverage (expressed as the percentage of population); and electricity access. The WRI-related access component of the DAPI can be observed in Fig. 4.

It must be stressed that the countries with the lowest DAPI access are located in Africa, together with Haiti, which occupied the 14th position with a value of 44, and Pakistan (25th position with 52). In the case of Haiti, the low access index is due to the low bandwidth,

Table 4 DAPI results by country group, according to the WRI from the World Risk Report 2019 (Mucke, 2019)

\begin{tabular}{|c|c|c|c|}
\hline $\begin{array}{c}\text { DISASTER RISK } \\
\text { CATEGORY (WRI) }\end{array}$ & MEAN DAPI & Minimum DAPI & Maximum DAPI \\
\hline Very high & $\mathbf{5 7 . 0}$ & 24.2 & 86.0 \\
\hline High & $\mathbf{5 4 . 5}$ & 25.8 & 91.7 \\
\hline Medium & $\mathbf{6 6 . 4}$ & 42.0 & 88.5 \\
\hline Low & $\mathbf{7 8 . 5}$ & 53.1 & 92.5 \\
\hline Very low & $\mathbf{8 5 . 2}$ & 68.4 & 95.8 \\
\hline
\end{tabular}

Mean, minimum, and maximum values 


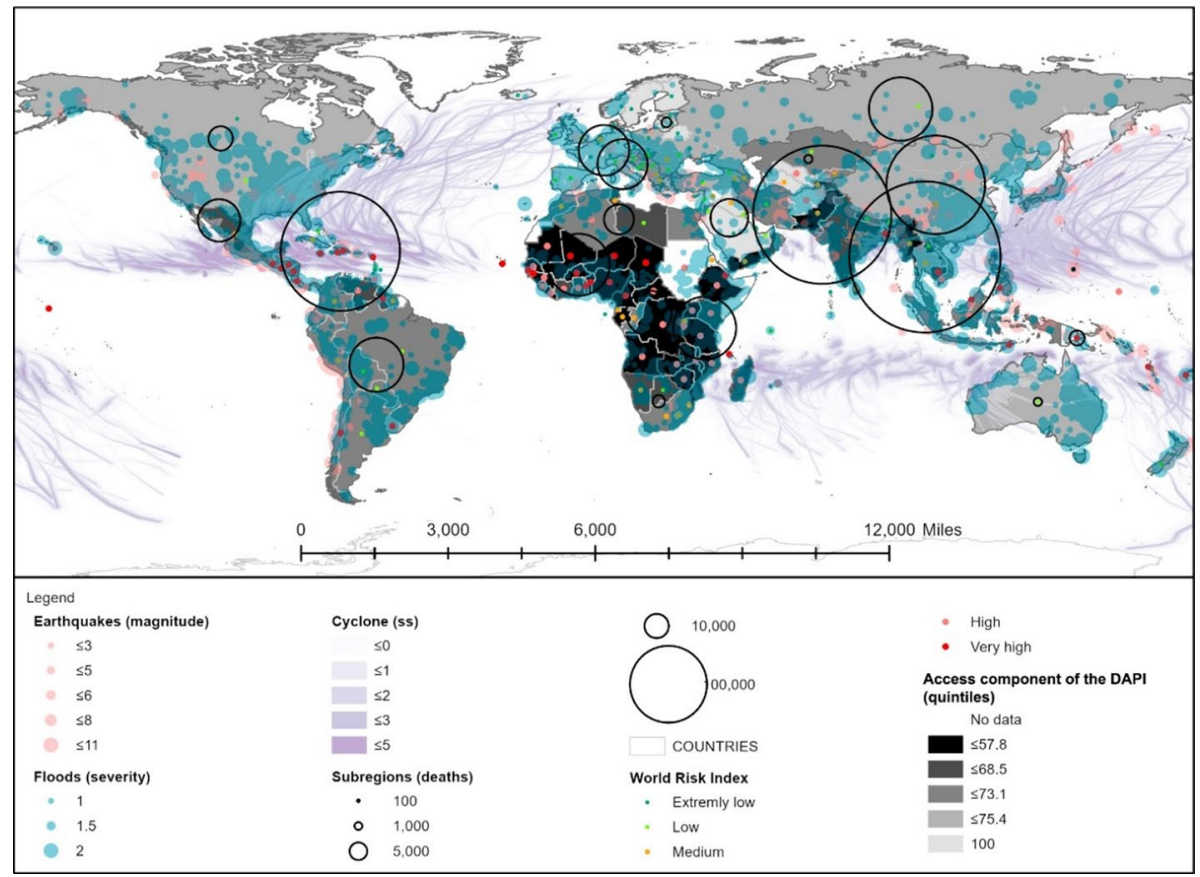

Fig. 4 Access component of the DAPI related to the WorldRiskIndex, natural events, and deaths by subregions. Subregions, flood events, major earthquakes, and cyclones as in Fig. 3. Shapefile countries: Esri, Garmin, CIA World Factbook (References: Regional and World Maps-The World Factbook-Central Intelligence Agency, 2020). Access component of the DAPI as explained in the methodology. WorldRiskIndex (WRI) from World Risk Report 2019 (Mucke, 2019), linked to countries by ISO code

although the rate of mobile phone access is $68 \%$ and the network coverage is $63 \%$. Hence, in this case, an improvement of the bandwidth and electricity would be a priority since only $45 \%$ of the population can benefit from it.

The subregions of South and Southeast Asia and the Caribbean stand out for their significant number of deaths. These areas display a DAPI access average of 66\%, 67\%, and $64 \%$, respectively. Nonetheless, South and Southeast Asia scored high rates of access to mobiles, electricity, and network coverage compared to the Caribbean, with the exception of Pakistan, which presented an access rate to mobile phones of 54\% and electricity of $71 \%$. Again, the authors highlight that country, region, and subregion-specific analyses must be conducted since, for instance, within the Caribbean subregion, the Dominican Republic catches the eye for its high rates of access, i.e. $81 \%, 99 \%$, and $100 \%$ of access to mobile phones, network coverage, and electricity access, respectively. Table 5 displays the correlation between the disaster risk classification according to the WRI and the mean DAPI access.

Even though the lowest disaster risk was found to often be linked to the highest technology development, this is not always the case, as happens with the maximum DAPI access value for very low disaster risk categories, as well as the minimum DAPI access values.

Thus, the relationship between said variables and the best course of action will be areaspecific. Given that the most vulnerable people have no access to electricity or internet connection, any strategy that is implemented must benefit large isolated areas and the community 
Table 5 DAPI access results by country group, according to the WRI from the World Risk Report 2019 (Mucke, 2019)

\begin{tabular}{|c|c|}
\hline $\begin{array}{c}\text { DISASTER RISK } \\
\text { CATEGORY (WRI) }\end{array}$ & $\begin{array}{c}\text { MEAN DAPI } \\
\text { access }\end{array}$ \\
\hline Very high & $\mathbf{5 8 . 5}$ \\
\hline High & $\mathbf{5 5 . 2}$ \\
\hline Medium & 67.4 \\
\hline Low & 72.7 \\
\hline Very low & 78.4 \\
\hline
\end{tabular}

\begin{tabular}{|c|c|}
\hline Maximum DAPI access & Minimum DAPI access \\
\hline 74.4 & 35.1 \\
\hline 87.9 & 13.9 \\
\hline 99.9 & 44.6 \\
\hline 99.0 & 67.4 \\
\hline 84.1 & 60.5 \\
\hline
\end{tabular}

Mean, minimum, and maximum values

as a whole. The analysis suggested that the use of digital applications is insufficient to ensure a timely response to natural hazards. Other alternatives such as television, radio, and community leaders education must be considered (Lindsay, 2011; Wahyu et al., 2012).

3.2.1.1 Usage component of the DAPI and risk The usage of mobile phones and internet is one of the key parameters in the proposal for mitigating risk disasters. As aforementioned, this component is based on the percentage of individuals using the internet as well as the active mobile broadband subscriptions per 100 inhabitants.

The results are plotted in Fig. 5, in which the darkest colour indicates the lowest value of the component. Africa stands out due to owning the lowest usage rate, followed by

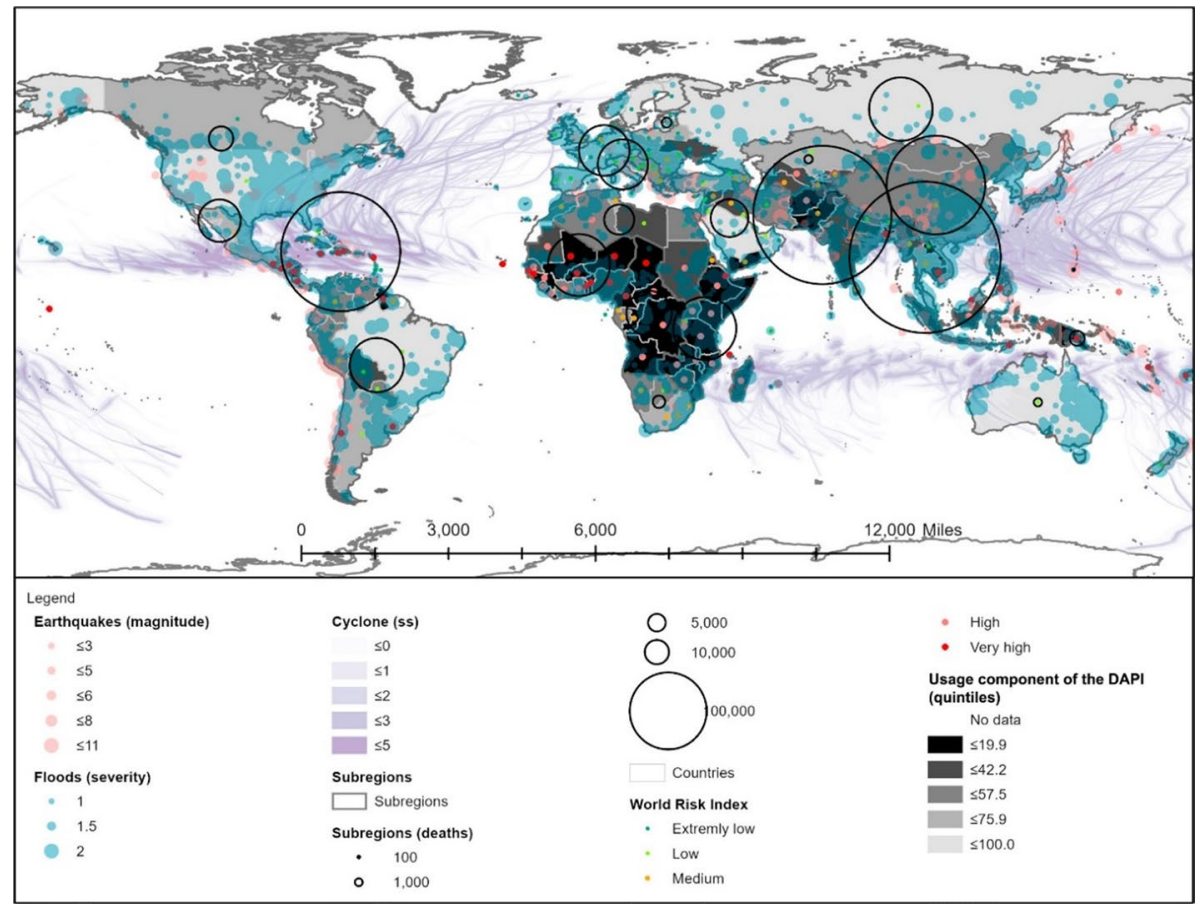

Fig. 5 Usage component of the DAPI (average of percentage of internet users and active mobile broadband subscribers per 100 inhabitants). Subregions, flood events, major earthquakes, and cyclones as in Fig. 3. Shapefile countries as in Fig. 4. Usage component of the DAPI as explained in the methodology. WRI as in Fig. 4 
countries in the Caribbean, Central America, and Asia, such as Haiti (16.3\%), Nicaragua (17.5\%), Tajikistan (17\%), Lao (19.9\%), and Nepal (21\%).

The last two regions are of great interest for their extremely high number of deaths. Among them, the lowest usage of technology was found in South Asia, Polynesia, Central Asia, and Central America, with an average DAPI usage component of 29.7\%, 35.4\%, $36.5 \%$, and $41.6 \%$, respectively. On the opposite end, there is the Caribbean, where the average usage is $51.1 \%$, albeit with a broad spread of usage data values between countries, ranging from $16 \%$ for Haiti to $75.9 \%$ for Saint Kitts and Nevis, and 57.2\% for the Dominican Republic.

Once more, when the disaster risk category is analysed together with the DAPI usage component (Table 6), there is no clear correlation regarding maximum and minimum values. The considerable differences between the riskiest countries compared to the ones with low risk are noteworthy. The use of technology is $41 \%$ lower in countries with a very high risk of disaster compared to the very low-risk ones. Yet, this cannot be explained by differences in accessibility, as these groups diverged only slightly in this regard, and thus, it can be stated that the use of technology is not linked to its access.

3.2.1.2 Skills component of the DAPI and risk The educational level of the population is another parameter that impacts its degree of understanding and subsequent capability of following advice, as well as the level of engagement between the emergency services and the population. In fact, the population may need training for following advice and reporting data (Homier et al., 2018). In this sense, the digital skill component indicates the population's familiarity degree with this type of technology, in that it evaluates the adult literacy rate (ITU, 2019), i.e. the capacity to read information, as well as the second and tertiary gross enrolment ratios, i.e. the number of students in relation to the number of people in school age, indicating their level of participation, and their possible role in an emergency situation. In this case, the lack of content in local languages could present a barrier that should also be taken into account (ITU, 2019).

Figure 6 shows that the lowest values of the DAPI skills component were achieved in Africa (Sub-Saharan region) and some countries of South Asia, such as Afghanistan (32.2\%) and Pakistan (37.5\%), with a subregional average of 54\%. Concerning the number of deaths, South Asia is the worst region among those with low skill rates. By contrast, the high skill rates in the Caribbean subregion can be highlighted, averaging $83.4 \%$, with a literacy rate of $97 \%$, a secondary enrolment rate of $95 \%$, and tertiary enrolment dropping to $48 \%$. This is shortly followed by Central America, with one of the lowest averaging rates, i.e. $67 \%$, and a tertiary enrolment of $33.9 \%$. The latter is akin to the rate achieved by Western Asia, achieving $74.2 \%$ on the skill component of the DAPI.

Table 6 DAPI usage results by country group, according to the WRI from the World Risk Report 2019 (Mucke, 2019)

\begin{tabular}{|c|c|c|c|}
\hline $\begin{array}{c}\text { DISASTER RISK } \\
\text { CATEGORY (WRI) }\end{array}$ & MEAN DAPI use & Maximum DAPI use & Minimum DAPI use \\
\hline Very high & $\mathbf{3 1 . 1}$ & 84.8 & 3.5 \\
\hline High & $\mathbf{3 2 . 5}$ & 100.0 & 4.3 \\
\hline Medium & $\mathbf{4 1 . 8}$ & 82.6 & 1.3 \\
\hline Low & $\mathbf{6 4 . 8}$ & 100.0 & 29.9 \\
\hline Very low & $\mathbf{7 6 . 5}$ & 100.0 & 19.9 \\
\hline
\end{tabular}

Mean, minimum, and maximum values 


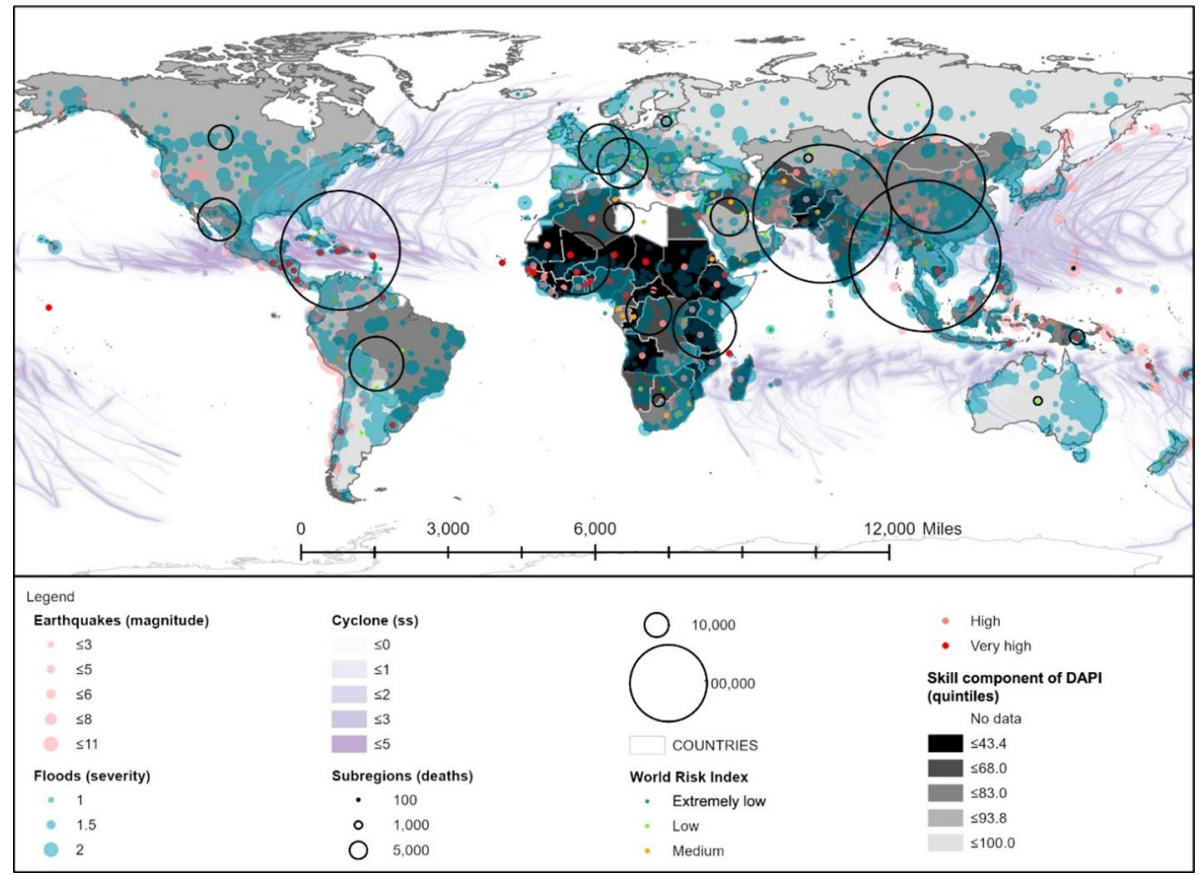

Fig. 6 Skill component of the DAPI (average of literacy rate and secondary and tertiary enrolment). Subregions, flood events, major earthquakes, and cyclones as in Fig. 3. Shapefile countries as in Fig. 4. Skill component of DAPI as explained in the methodology. WRI as in Fig. 4

According to the WRI, the highest risk countries exhibited high rates of literacy of about $86.4 \%$, which decreased to an average of $75 \%$ for the secondary enrolment. In the case of tertiary enrolment, however, values plunged to $25.9 \%$. The worst values among the top ten countries were found for Guatemala, Bangladesh, and Papua New Guinea, with a DAPI skills component of $52 \%, 52.6 \%$, and $55.2 \%$, respectively.

The correlation between the disaster risk category and the skills component of the DAPI can be observed in Table 7: The countries with a very high risk showed the lowest maximum and minimum skills category of the DAPI compared to the remaining ones. In spite of this, anew the very high and high disaster risk categories exhibited a substantial data range that narrows down as the risk of the category decreases, and therefore recommendations should be case-specific.

3.2.1.3 Affordability component of the DAPI and risk The main limitation associated with the use of mobile apps lies in the technology cost (ICT et al., 2019). The cost of the low data and voice basket consumption expressed relative to the GNI p.c. strongly differs between developed countries ( $1 \%$ of the GNI p.c.), developing countries ( $7.5 \%$ of the GNI p.c.), and least developed countries (17\%). In addition, in the latter two cases, the price difference with respect to low and high data and voice basket consumption is noteworthy, with low data and voice basket consumption being very prevalent in low-income countries (ICT et al., 2019). For this reason, this category was considered as a reference for the affordability component of the DAPI (Table 3). A price reduction would accelerate the increase in mobile phone 
Table 7 DAPI skills results by country group, according to the WRI from the World Risk Report 2019 (Mucke, 2019)

\begin{tabular}{|c|c|c|c|}
\hline $\begin{array}{c}\text { DISASTER RISK } \\
\text { CATEGORY (WRI) }\end{array}$ & MEAN DAPI skills & Maximum DAPI skills & Minimum DAPI skills \\
\hline Very high & $\mathbf{5 8 . 3}$ & 96.5 & 16.1 \\
\hline High & $\mathbf{5 3 . 1}$ & 100.0 & 18.5 \\
\hline Medium & $\mathbf{6 8 . 7}$ & 100.0 & 32.6 \\
\hline Low & $\mathbf{8 3 . 8}$ & 100.0 & 56.5 \\
\hline Very low & $\mathbf{8 7 . 2}$ & 100.0 & 47.5 \\
\hline
\end{tabular}

Mean, minimum, and maximum values

penetration (ICT et al., 2019), albeit not being the only key aspect. Additional ones, such as the educational level and the use of local languages, should also be taken into account (ICT et al., 2019). Figure 7 illustrates the inverse correlation between the highest DAPI values and the lowest consumer affordability, thus revealing a low potential for introducing mobile apps in those areas.

The lowest values related to the affordability component of the DAPI were found in South America, with an average of 2.9. For its part, the regions with the highest death rate, i.e. Southeast Asia, South Asia, and the Caribbean, exhibited an average of 2.6, 3.0, and, 4.4, respectively. Nonetheless, there are high discrepancies within them, in particular

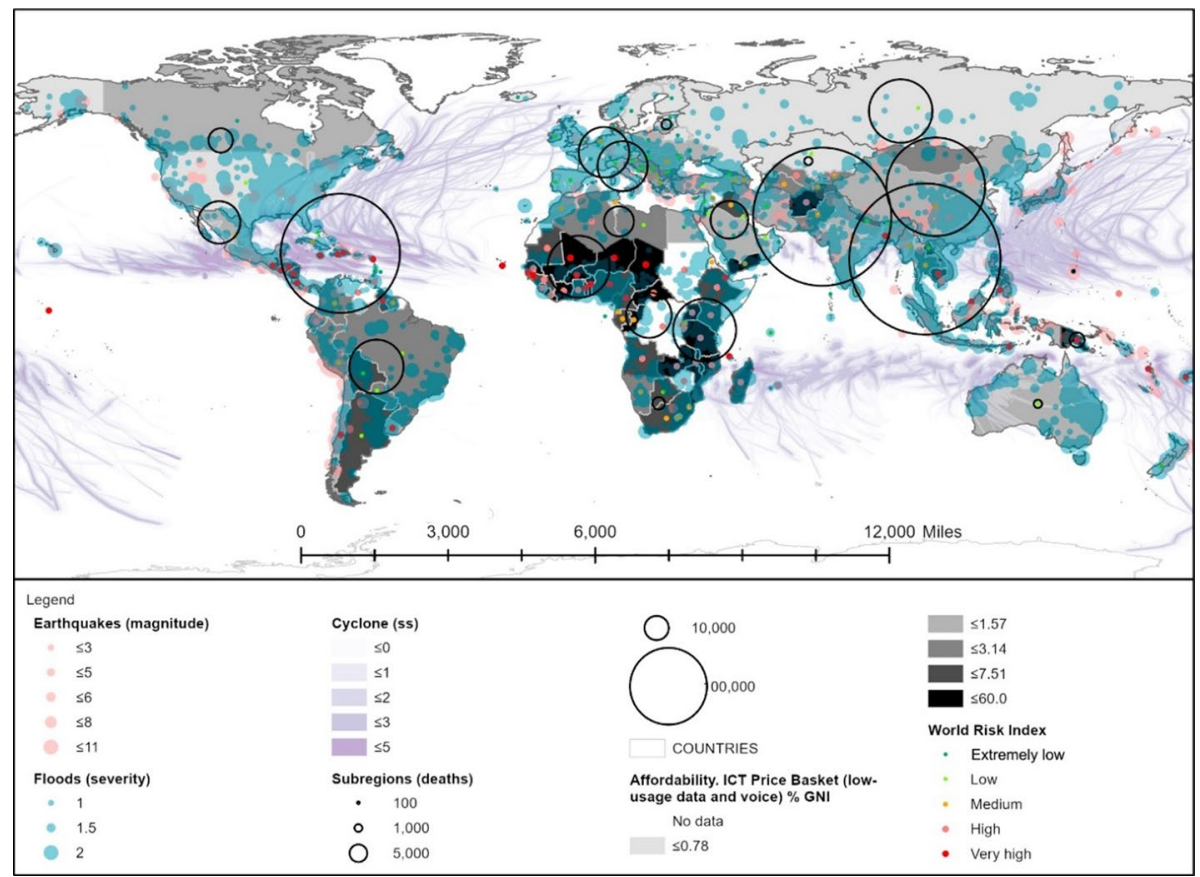

Fig. 7 Affordability component of the DAPI (mobile data and voice low-usage basket) related to the WorldRiskIndex, natural events, and deaths by subregion. Subregions, flood events, major earthquakes, and cyclones as in Fig. 3. Shapefile countries as in Fig. 4. Access to electricity: percentage of the population with access to electricity. Affordability of mobile data and voice low-usage basket, as a percentage of GNI per capita. WRI as in Fig. 4 
Table 8 Results by country group, according to the WRI from the World Risk Report 2019 (Mucke, 2019)

\begin{tabular}{|c|c|c|c|}
\hline $\begin{array}{l}\text { DISASTER RISK } \\
\text { CATEGORY } \\
\text { (WRI) }\end{array}$ & $\begin{array}{l}\text { MEAN LOW } \\
\text { CONSUMPTION DATA } \\
\text { AND VOICE BASKET }\end{array}$ & Maximum & Minimum \\
\hline Very high & 11.3 & 0.6 & 56.8 \\
\hline High & 12.0 & 0.8 & 60.0 \\
\hline Medium & 4.6 & 0.4 & 49.0 \\
\hline Low & 2.0 & 0.3 & 5.6 \\
\hline Very low & 1.0 & 0.1 & 4.6 \\
\hline
\end{tabular}

Mean, minimum, and maximum values. Consumption expressed as a percentage of GNI per capita. Created by the authors, adapted from ITU, 2019 and WRI 2019

regarding Haiti with 13.8 and Barbados with 1.6 in the case of the Caribbean, and Afghanistan with 13.5 compared to the 0.44 for Sri Lanka in South Asia.

Furthermore, when the average consumption is contrasted with the WRI disaster risk category (Table 8), it can be observed that only countries with low and very low risk of disasters related to natural hazards maintain affordable prices below $2 \%$ of the GNI p.c. In what high and very high-risk countries are concerned, the mean cost amounts to $11.3 \%$ and nearly $12 \%$ of the GNI p.c. (Table 8 ) with peaks in African countries, such as Liberia (60\%), Niger (56.8\%), and Central African Republic (48.1\%). Among the highest risk countries, Papua New Guinea (22.2\%), Central America (Guatemala 10.9\%), Honduras (10.4\%), Nicaragua 9\%), as well as Haiti (13.8\%) and Afghanistan (13.5\%) stand out. Southeast Asia is an area of particular interest for its affordability values, with values of $2.5 \%$, while pertaining to a high-risk category.

\subsubsection{Evaluation of each type of natural risk and the DAPI}

Complementarily to the previous analysis, the DAPI was evaluated in relation to the type of natural events. Earthquakes, cyclones, and floods were considered separately.

3.2.2.1 Earthquakes and the DAPI In Fig. 8, the earthquake magnitude was overlaid with the DAPI. In the Caribbean area, the DAPI exhibited high values and high death rates linked to this type of natural event. Hence, technology should be considered as a strategy tool for risk disaster mitigation. The same applies to China, whose DAPI value stands at a medium range.

However, this strategy would not be feasible for some areas, such as Pakistan and Afghanistan, for which the number of mobile subscriptions (per 100 people) is $73 \%$ and $59 \%$, respectively, but the number of internet users drops to $16 \%$ and $14 \%$, respectively (World Bank Open DatalData, 2020). This is also true for other areas, such as Syria, where mobile subscriptions amount to 13.61 million, i.e. $74 \%$ of its population, yet the number of internet users reduces to only $33 \%$ of the country's population (World Bank Open DatalData, 2020).

This evaluation demonstrated anew that area-specific analyses are required. For instance, in some earthquake-prone countries such as Singapore, the number of mobile subscriptions is 8.37 million, which represents $144 \%$ of the population, and internet users are high, with $84 \%$ penetration (World Bank Open DatalData, 2020). Therefore, in some countries, the appropriate measures will heavily rely on traditional media resources, such as television and radio advertisements, rather than mobile phones. 


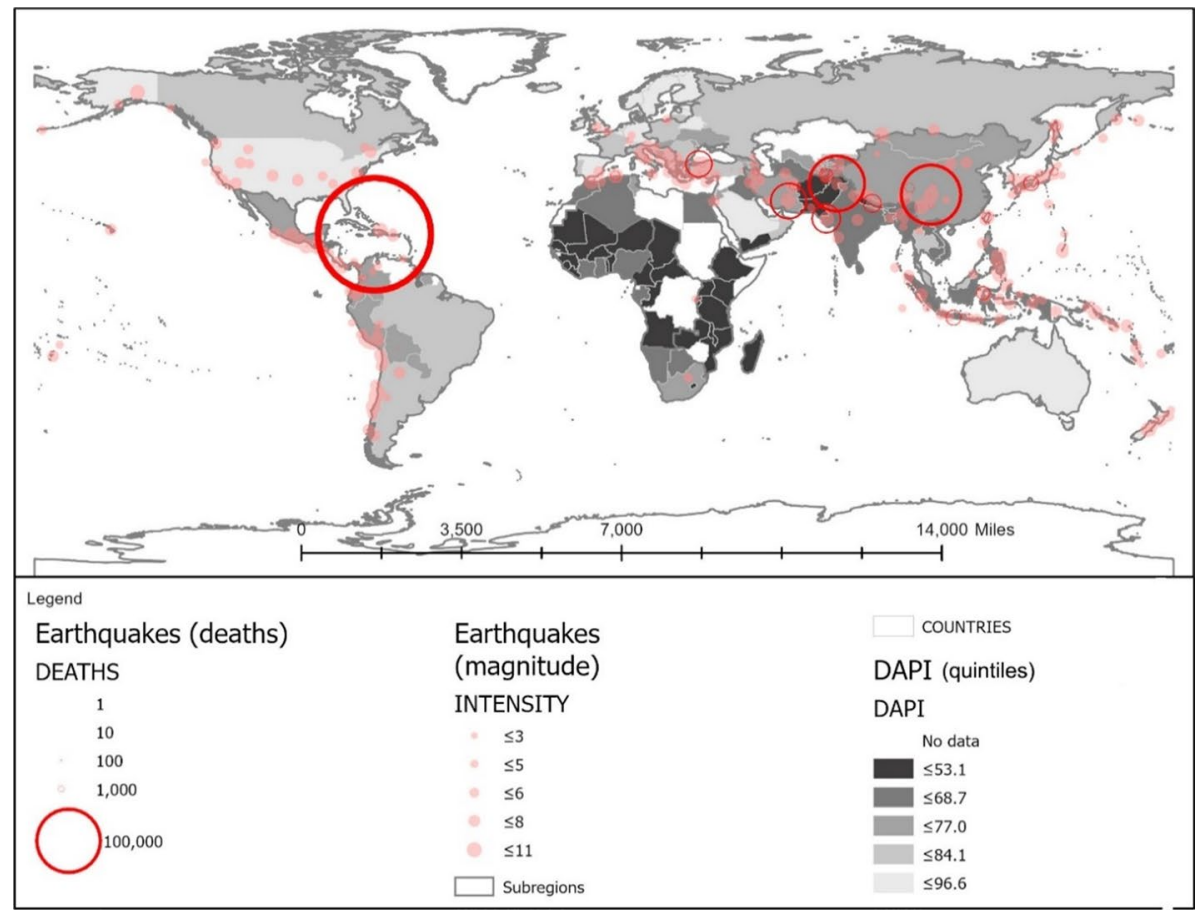

Fig. 8 Correlation between earthquakes and the DAPI in each country. Subregions, major earthquakes by deaths, and severity as in Fig. 3. Shapefile countries as in Fig. 4. DAPI as explained in the methodology

3.2.2.2 Hurricane and cyclone risk and the DAPI Concerning hurricanes and cyclones (Fig. 9), a correlation was found between the DAPI in very high or high-scoring countries and the risk of natural hazards. In general, mobile apps can be considered an interesting tool, among others. The high expense brought about by internet connection must be taken into account while devising the implementation for mobile apps. In fact, in some countries, such as Haiti, while mobile subscriptions account for $61 \%$ of the population (6.85 million), internet users are reduced to 19\%, with 2.1 million (World Bank Open DatalData, 2020).

Mozambique and Madagascar are the exceptions to the rule, as being a high-risk country does not seem to relate to DAPI high values, therefore excluding the possibility of technology use.

3.2.2.3 Flooding risk and the DAPI India, Nepal, Bangladesh, Cambodia, and some areas of China are the most vulnerable to floods (Fig. 10), and their DAPI was 57, 53, 54, 60, and 74, respectively. The affordability indicator for Bangladesh and India is noteworthy, at 1.4 and 0.9 , respectively, with a price reduction strategy being a possible option for both of these cases. Their affordability data correlated with their usage of mobile technology, with $14.25 \%$ in Bangladesh and $22 \%$ in India, similar to the $21 \%$ found for Nepal, in spite of scoring higher (4.6) on the ICT Price Basket (ICT et al., 2019). The remaining parameters exhibited quite similar values.

Apropos of the death rate, the high-flooding risk of Myanmar is striking. The mobile phone coverage reaches $114 \%$ of its population, which falls to $31 \%$ when it comes to 


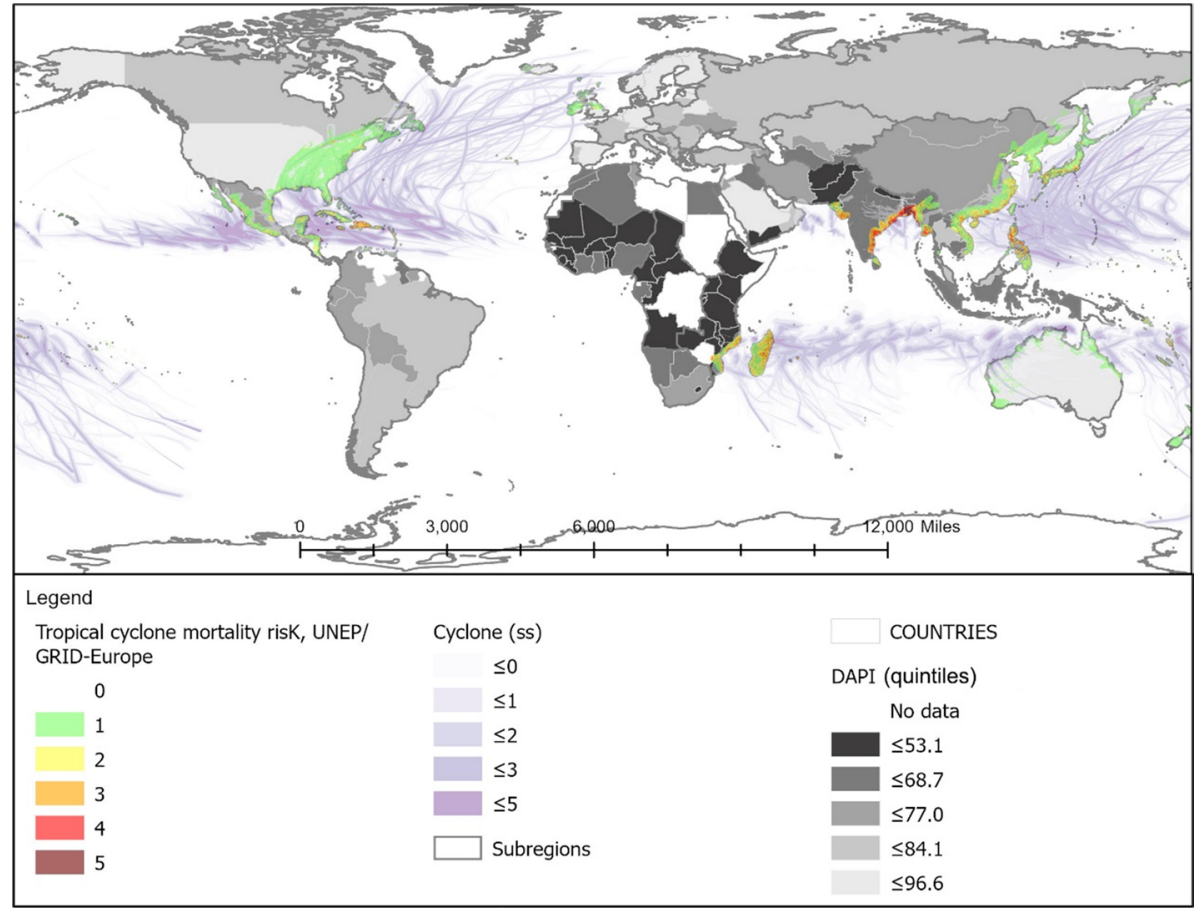

Fig. 9 Correlation between cyclone risk and the DAPI in each country. Subregions, cyclones by category as in Fig. 3. Shapefile countries as in Fig. 4. Tropical cyclone mortality risk by UNEP/GRID-Europe (Global Risk Data Platform, 2020). Estimation of the global risk induced by tropical cyclone hazard. The scale of the estimated risk index ranges from 1 (low) to 5 (extreme). This product was designed by UNEP/GRIDEurope for the Global Assessment Report on Risk Reduction (GAR). DAPI as explained in the methodology.

internet users. In like manner, Laos has a mobile subscription of $81 \%$ of the population, compared to $39 \%$ of internet users, i.e. 2.7 million people.

\subsubsection{Other aspects to take into account}

A limitation that should be taken into consideration when aiming to reach the largest number of people possible is the language barrier (Fig. 11). English is the most widely spoken language (1,500 million) (Statista Database, 2020) and the most commonly used on the internet (Internet World Stats-Usage and Population Statistics, 2020), yet it is the native language of only $5.3 \%$ of the population (Worlddata: The World in Numbers, 2020). This excludes the population with a lesser degree of academic training, which usually matches the most vulnerable to natural hazards and, therefore, those most in need of risk-mitigating apps. In 2016, the number of registered illiterates achieved $13.75 \%$ of the population (Our World in Data, 2020). From this point of view, the use of local languages has been identified as an additional aspect that impacts the effective use of the internet (ITU, 2019) and, by extension, that of mobile apps. 


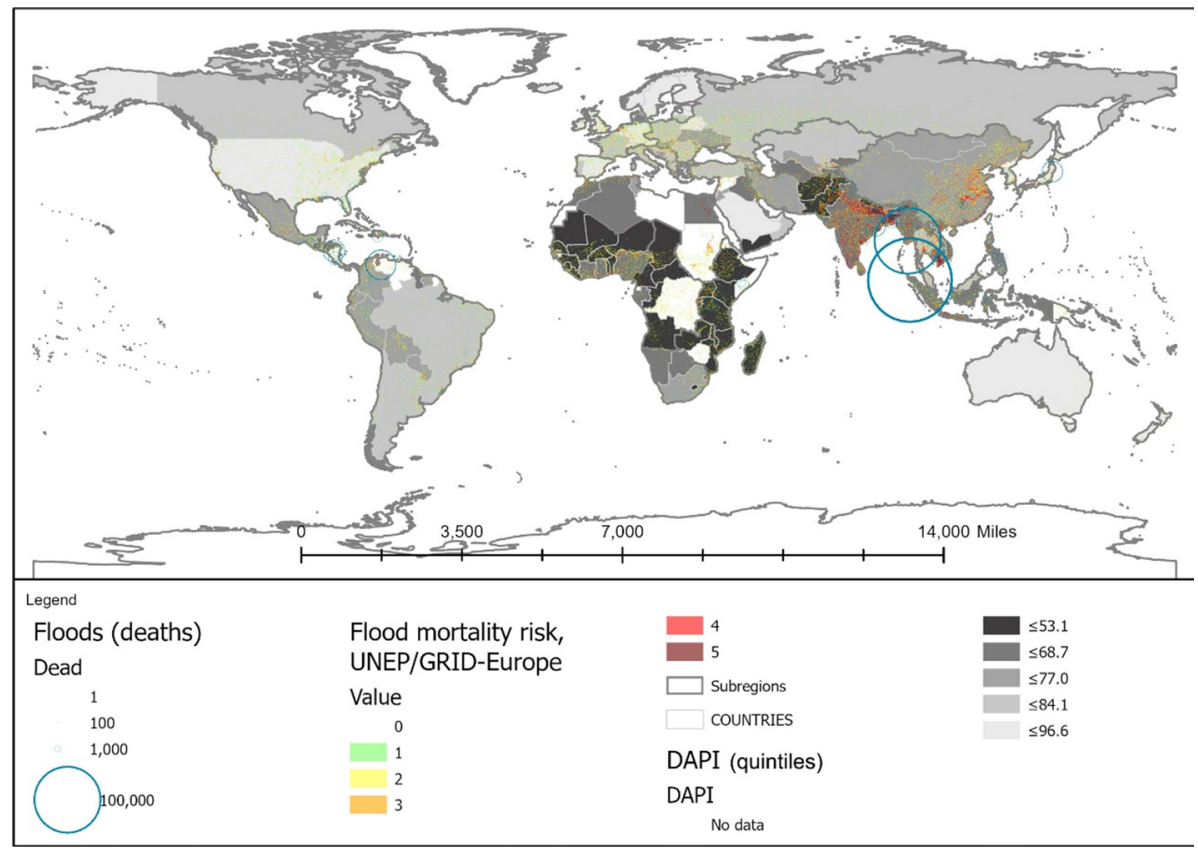

Fig. 10 Correlation between flooding risk and the DAPI in each country. Subregions, floods by severity and deaths as in Fig. 3. Shapefile countries as in Fig. 4. Flood risk by UNEP/GRID-Europe. Estimation of the global risk induced by flooding. The scale of the estimated risk index ranges from 1 (low) to 5 (extreme). Designed by UNEP/GRID-Europe for the Global Assessment Report on Risk Reduction (GAR). DAPI as explained in the methodology

Figure 11 illustrates the correlation between natural events and the use of indigenous languages. According to it, Papua New Guinea and Indonesia hold the highest amount of living languages, and henceforth, the use of dialects and different languages must be considered in the development of apps. The adaptation to local languages would also be required for scarce linguistic-variability areas, such as the Caribbean region.

Along the same line, Table 9 highlights that the highest linguistic variety takes place in the areas with a very high and high disaster risk. This entails that any efficient tool must be adapted to local and indigenous languages to reach the highest possible percentage of population.

Despite the relevance of languages, the download platforms of apps do not provide information on the dialects in which these can be used. It is an important parameter to take into account for app development. At the same time, apps must be developed with a simple and intuitive graphical user interface, adapted to people with reading difficulties, and facilitate communication by audio for blind and illiterate people. 


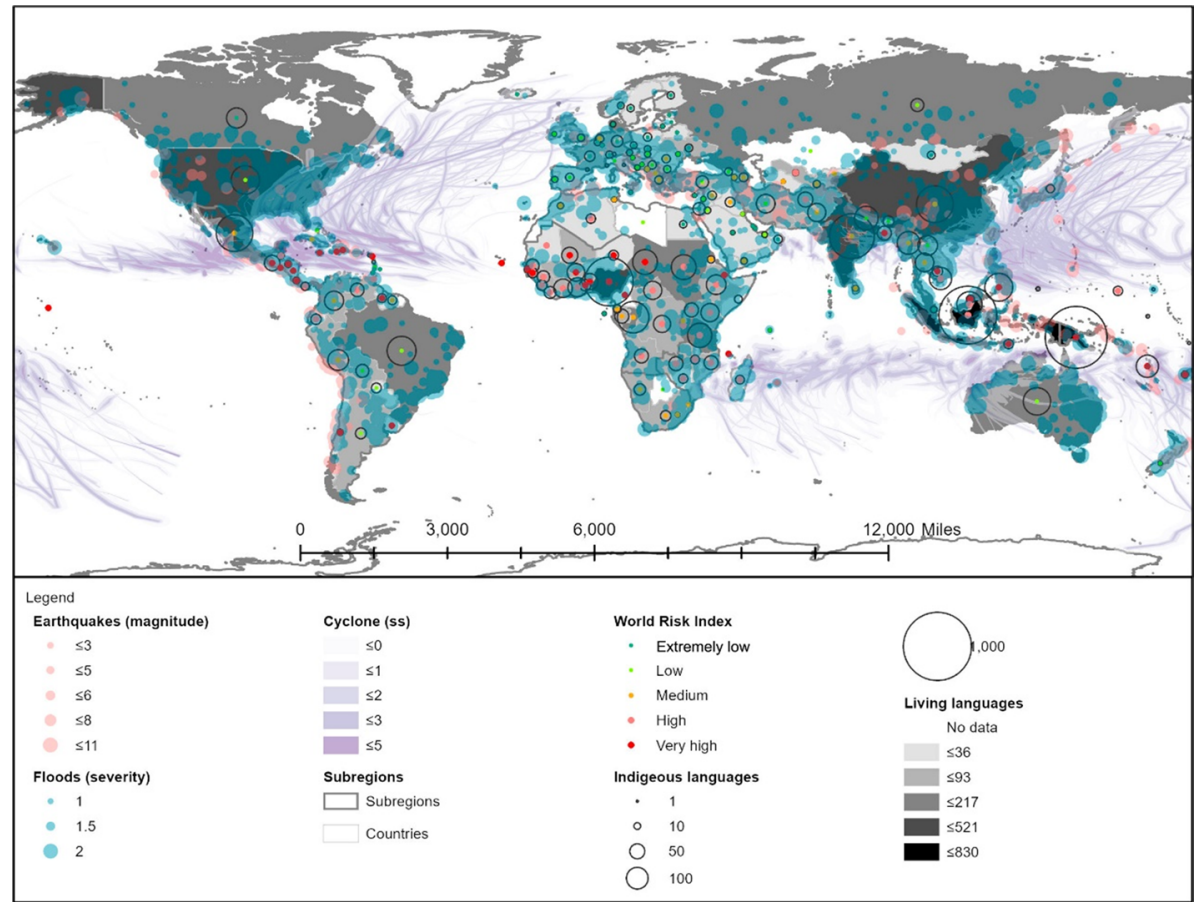

Fig. 11 Languages and risk. Subregions, flood events, major earthquakes, and cyclones as in Fig. 3. Shapefile countries as in Fig. 4. WRI: as in Fig. 4. Living and indigenous languages (Ethnologue: Languages of the World, 2020; UNESCO Atlas of the World's Languages in Danger, 2020)

Table 9 Languages by country group, according to the WorldRiskIndex from the World Risk Report 2019 (Mucke, 2019)

\begin{tabular}{|c|c|c|c|c|c|c|}
$\begin{array}{c}\text { WRI } \\
\text { CATEGORY }\end{array}$ & $\begin{array}{c}\text { MEAN } \\
\text { living } \\
\text { languages }\end{array}$ & $\begin{array}{c}\text { Minimum } \\
\text { living } \\
\text { lang. }\end{array}$ & $\begin{array}{c}\text { Maximum } \\
\text { living } \\
\text { lang. }\end{array}$ & $\begin{array}{c}\text { Mean } \\
\text { indig. } \\
\text { Lang. }\end{array}$ & $\begin{array}{c}\text { Minimum } \\
\text { indig. } \\
\text { lang. }\end{array}$ & $\begin{array}{c}\text { Maximum } \\
\text { indig. } \\
\text { lang. }\end{array}$ \\
\hline Very high & 70.8 & 2 & 830 & 66.5 & 2 & 830 \\
\hline High & 68.7 & 4 & 722 & 63.6 & 3 & 719 \\
\hline Medium & 67.0 & 2 & 445 & 59.8 & 2 & 438 \\
\hline Low & 53.3 & 2 & 364 & 35.0 & 2 & 181 \\
\hline Very low & 23.2 & 0 & 169 & 10.9 & 0 & 86 \\
\hline
\end{tabular}

Living and indigenous languages based on Ethnologue (Ethnologue: Languages of the World, 2020) and UNESCO (UNESCO Atlas of the World's Languages in Danger, 2020)

\section{Conclusions}

The preliminary evaluation of the types of mobile apps evidenced that most of the apps limit their coverage range to only one stage of Disaster Risk Management (DRM) and one type of hazard event. In general, pre-disaster apps are based on warnings and advice on how to proceed against risks, while trans-post-disaster ones mainly locate citizens, which could be improved by combining it with different possibilities such as collaborative mapping and the Internet of Things. Adopting a separate approach to cope with distinct hazards and phases of risk management does not match the risk reality, which, as aforementioned, 
is complex and systemic, with a strong interrelationship between different types of components and actors. In addition, only $28-36 \%$ of the pre- and trans-post-event apps allow the sharing of information through other social networks or SMS. This reduces efficiency, making it more difficult to coordinate a humanitarian response, communicate, establish a relationship with forecasting models and spatial-temporal advice and detection systems, and strengthen local coping capacities among regions.

Most apps were developed by private companies with non-transparent information management and ambiguous privacy policies. The results of the analysis highlighted the need for robust policies that promote reliability, transparency, and citizen empowerment and control over their data, which must be provided by a strong public service with a holistic approach.

To evaluate the potential of mobile apps as disaster-mitigating tools regarding natural events, a Digital Application Potential Index (DAPI) was created. The DAPI offers both a general overview and in-depth details on specific topics within its four categories: access to technology, its usage, skills, and affordability at a regional scale. This index has been cross-referenced with the WRI to evaluate the viability of this technology in areas with different rates of disaster risk. A general tendency that could be identified in this analysis lied in the fact that when countries were grouped according to their risk category (based on the WRI), the higher the disaster risk the lower the DAPI. Furthermore, a significant dispersion of data was yielded, albeit with variations between specific DAPI categories. Regarding the DAPI components, one of the main drawbacks uncovered was affordability, which revealed that only countries with low and very low risk of natural event-related disasters maintain affordable prices below $2 \%$ of GNI p.c. The mean price for countries with a very high and high disaster risk was $11.3 \%$ and nearly $12 \%$ of GNI p.c., respectively. The price reduction in the latter together with electricity and broadband access will contribute to a fast increase in mobile phone penetration. In addition, since countries with very high and high disaster risk exhibited a significant number of local and indigenous languages, tools must be adapted to their specific languages and dialects to reach the highest amount of people, especially the most vulnerable. In addition, a clear app layout must be prioritised to reach both the illiterate and the poorest population with lower literacy rates.

The policies to implement the use of mobile apps as tools for Risk Disaster Management must consider reducing the prices of internet connection while increasing educational levels and the language translation of the apps. Their current use falls far short of ensuring communication in Disaster Risk Management and a timely response to natural hazards, especially in countries with a higher level of disaster risk. Other alternatives such as television, radio, and SMS must still be considered.

The index developed has provided interesting recommendations for specific cases, although the same was not true at the global scale, due to the strong divergence of circumstances within each country when these are grouped by risk level. Thus, a detailed study at a regional scale using DAPI is warranted, including each of its components. This would result in more precise recommendations for each geographical area.

Complementarily to this, and as a future line of research, it would be pivotal to evolve from isolated sectoral applications to public digital ecosystem platforms that integrate different tools, levels, and actors for the coordinated operation of integrated disaster risk management. 
Author contributions MMB-B and LNC helped in design of the research and ICT and risk management aspects; JR and AC analysed the app; LNC contributed to GIS and graphs; LNC and JR managed the data; all authors contributed to the discussion of results and writing of the manuscript.

Funding Open Access funding provided thanks to the CRUE-CSIC agreement with Springer Nature. This research has been developed within the project "Plataforma de Monitoreo de daños en tiempo real para un primer nivel de evaluación de daños de vivienda y servicios y respuesta rápida", granted by Universidad Politécnica de Madrid under the call "XIX Convocatoria UPM para acciones para contribuir al cumplimiento de los objetivos de desarrollo sostenible", and co-funded by Arcoíris NGO.

Data availability Database has been provided.

\section{Declarations}

Conflicts of interest The authors declare that they have no conflict of interest.

Open Access This article is licensed under a Creative Commons Attribution 4.0 International License, which permits use, sharing, adaptation, distribution and reproduction in any medium or format, as long as you give appropriate credit to the original author(s) and the source, provide a link to the Creative Commons licence, and indicate if changes were made. The images or other third party material in this article are included in the article's Creative Commons licence, unless indicated otherwise in a credit line to the material. If material is not included in the article's Creative Commons licence and your intended use is not permitted by statutory regulation or exceeds the permitted use, you will need to obtain permission directly from the copyright holder. To view a copy of this licence, visit http://creativecommons.org/licenses/by/4.0/.

\section{References}

Abarca-Alvarez, F. J., Reinoso-Bellido, R., \& Campos-Sánchez, F. S. (2019). Decision model for predicting social vulnerability using artificial intelligence. ISPRS International Journal of Geo-Information, $8(12), 575$.

ANSS - Advanced National Seismic System. (2020). Retrieved 16 July 2020, from https://www.usgs.gov/ natural-hazards/earthquake-hazards/anss-advanced-national-seismic-system?qt-science_support_ page_related_con=4\#qt-science_support_page_related_con

Arce, M. F., Córdoba, A. C., \& UNESCO. (2012). Las TIC y la gestión del riesgo a desastres. Hacia La Sociedad de La Información y El Conocimiento.

Arshad, B., Ogie, R., Barthelemy, J., Pradhan, B., Verstaevel, N., \& Perez, P. (2019). Computer vision and IoT-based sensors in flood monitoring and mapping: A systematic review. Sensors, 19(22), 5012. https://doi.org/10.3390/s19225012

Association, G. S. M. (2020). The mobile economy-2020. GSMA Intelligence, 30.

Bachmann, D. J., Jamison, N. K., Martin, A., Delgado, J., \& Kman, N. E. (2015). Emergency preparedness and disaster response: There's an app for that. Prehospital and Disaster Medicine, 30(5), 486-490. https://doi.org/10.1017/S1049023X15005099

Brakenridge, G. R. (n.d.). Global Active Archive of Large Flood Events-Humanitarian Data Exchange. Dartmouth Flood Observatory (DFO). Retrieved 16 July 2020, from https://data.humdata.org/dataset/ global-active-archive-of-large-flood-events

Cardona Arboleda, O. D. (2008). Medición de la gestión del riesgo en América Latina. Revista Internacional De Sostenibilidad, Tecnología y Humanismo, 3, 1-20.

Cardoso, D., Santos, G. S. P., Rezende, M. S. C., da Bello, J., \& S. A., \& Franzoni, A. M. B. . (2014). Gestão do conhecimento nas respostas a desastres naturais: A experiência da Defesa Civil do Estado de Santa Catarina. Perspectivas Em Gestão \& Conhecimento, 4(2), 90-106.

Chang, H., \& Franczyk, J. (2008). Climate change, land-use change, and floods: Toward an integrated assessment. Geography Compass, 2(5), 1549-1579. https://doi.org/10.1111/j.1749-8198.2008.00136.x

Cioca, M., Cioca, L.-I., \& Mihaescu, L. (2009). Infrastructure and system programming for digital ecosystems used in natural disaster management. 2009 3rd IEEE International Conference on Digital Ecosystems and Technologies (DEST), 73-78. https://doi.org/10.1109/DEST.2009.5276774

Coppola, D. P. (2011). Introduction to International Disaster Management. Elsevier. 
CRED, C. for R. on the E. of D., \& USAID, U. S. A. for I. D. (2020). Disaster 2019: Year in Review. Cred Crunch Newsletter.

Dartmouth Flood Observatory. (2020). Retrieved 16 July 2020, from http://floodobservatory.colorado.edu/ Archives/index.html

Doktor, C., \& Giroux, J. (2011). Factsheet 6: The changing dynamics of crisis communication. $3 R G$ REPORT, 22.

Dunn Cavelty, M., \& Giroux, J. (2011). Crisis mapping: A phenomenon and tool in emergencies. CSS Analyses in Security Policy, 103.

Economy, N. C. (2018). Unlocking the inclusive growth story of the 21 st century: Accelerating climate action in urgent times. Retrieved on, 3, 18 .

Ethnologue: Languages of the World. (2020). Retrieved 16 July 2020, from https://www.ethnologue. com/?_cf_chl_captcha_tk_=661cf505bc4337c63750bb17ccf26351bca1d74a-1594925793-0-AaQqv p4W035s716mmwwvPbqUgRSEvxgyxKiT-yusFIBvOF2Td_3uyrwsjuVTg9cGHIp8ivU0KkFxIpEG BE4-307Cb_wUL_syDDUDUrSDxMfhlJcr1k1a3s5bJUBWXhB1IpTyEJskxRN9dkz0VTE8Gfqnp9 MkGJFgkgGX58xGpwoZE09_Q4WECO0ASMSH6qKp7hGV7MOWr5BdEPCC4912ozFCkH611 NSOQAX_ryRSqJD4n291zqGWb4I0mRYXRDrId_o51APQGWWHJ8PFC0ZKyez_RYIenRwVSn M8Vo6hFM1EQujgrBHKL16qtstq-zLKanf0yA-NSaryfpZ2mJtncKIG5rJD8dBXIL7FxK0VaU3ZIWs 2aqWriN0k7q0FkSff31OF4q206VGTDB1PaEqF2yDBTFXUtoB-_kUsn0bSB3gsuoKEb8tLWUjZLJ Z8pj6C9uNFjxWTkqJEdpUxrEaAB112Feo5LINUDf8bE67TsCGj

Evans, G. W. (2019). Projected behavioral impacts of global climate change. Annual Review of Psychology, 70(1), 449-474. https://doi.org/10.1146/annurev-psych-010418-103023

Foresti, A. J. (2015). Um arranjo interdisciplinar para gestão de riscos de desastres socionaturais com base na engenharia de resiliência.

Giroux, J., Hagmann, J., \& Cavelty, M. D. (2009). Focal Report 3: Risk Analysis. Risk Analysis, 27.

Giroux, J., Roth, F., \& Herzog, M. (2013). Using ICT \& social media in disasters: Opportunities \& risks for government. CSS Risk and Resilience Reports.

Global Risk Data Platform. (2020). Retrieved 16 July 2020, from https://preview.grid.unep.ch/index.php? preview $=$ data\&events $=$ cyclones $\&$ evcat $=9 \&$ lang $=$ eng

Google. (2020). Select a category and tags for your app or game. In Play console help.

Grassau, D., Puente, S., Vatter, N., \& Rojas, R. (2019). Perfiles y roles de los conductores de TV en momentos de desastres: Propuesta conceptual a partir del caso del terremoto del $27 \mathrm{~F}$ en Chile. Revista de Comunicación, 18(2), 155-176.

Guha-Sapir, D., Below, R., \& Hoyois, P. (2015). EM-DAT: International disaster database. Catholic University of Louvain: Brussels, Belgium, 27(2015), 57-58.

Homier, V., Hamad, R., Larocque, J., Chassé, P., Khalil, E., \& Franc, J. M. (2018). A randomized trial comparing telephone tree, text messaging, and instant messaging app for emergency department staff recall for disaster response. Prehospital and Disaster Medicine, 33(5), 471-477. https://doi.org/10.1017/ S1049023X18000912

Hong, L., Fu, C., Torrens, P., \& Frias-Martinez, V. (2017). Understanding citizens' and local governments' digital communications during natural disasters: The case of snowstorms. The 2017 ACM, https://doi. org/10.1145/3091478.3091502

Hongbo, W., Bárcena, A., Kituyi, M., Heyzer, N., Lopes, C., Khalaf, R., \& Alkalaj, S. (2014). World Economic Situation Prospects 2014. United Nations publication.

ICT, I. T., DKH, D. K. H. D., \& ITU, T. D. B. of the I. T. U. (2019). Measuring Digital Development: ICT Price Trends 2019.

Internet World Stats-Usage and Population Statistics. (2020). Retrieved 16 July 2020, from https://www. internetworldstats.com/

ITU, T. D. B. of the I. T. U. (2003). Digital Access Index. ITU.

ITU. (2017). Measuring the Information Soceity Report 2017 (Vol. 1). International Telecommunication Union.

ITU, T. D. B. of the I. T. U. (2018). Measuring the information society report (Vol. 2). ICT country profiles.

ITU. (2019). The ICT Development Index (IDI) Methodology. International Telecommunication Union, February: Indicators and Definitions.

ITU, T. D. B. of the I. T. U. (2020). Statistics. In Statistics.

Johnson, S. M. (1998). The Internet changes everything: Revolutionizing public participation and access to government information through the Internet. Admin. L. Rev., 50, 277.

Karagkiozidou, M., Ziakis, C., Vlachopoulou, M., \& Kyrkoudis, T. (2019). App Store Optimization Factors for Effective Mobile App Ranking (pp. 479-486). Cham: Springer. 
Karanci, A. N., Aksit, B., \& Dirik, G. (2005). Impact of a community disaster awareness training program in Turkey: Does it influence hazard-related cognitions and preparedness behaviors. Social Behavior and Personality: An International Journal, 33(3), 243-258. https://doi.org/10.2224/sbp.2005.33.3.243

Kemper, J., \& Kolkman, D. (2019). Transparent to whom? No algorithmic accountability without a critical audience. Information, Communication and Society, 22(14), 2081-2096. https://doi.org/10.1080/13691 18X.2018.1477967

Layek, A. K., Pal, A., Saha, R., \& Mandal, S. (2018). DETSApp: An app for disaster event tweets summarization using images posted on twitter. Fifth International Conference on Emerging Applications of Information Technology (EAIT), 2018, 1-4. https://doi.org/10.1109/EAIT.2018.8470398

Lindsay, B. R. (2011). Social media and disasters: Current uses, future options, and policy considerations. 13.

Ludwig, L., \& MATTEDI, M. A. (2018). The information and communication technologies in the risk management of social and environmental disasters. Ambiente and Sociedade. https://doi.org/10.1590/18094422asoc0103r4vu1811ao

Mucke, P. (2019). World risk index 2019. In Berlin, Germany: Bündnis Entwicklung Hilft. Institut für Friedenssichrungsrecht und Humanitares Völkerrecht (IFHV).

Norris, W. (2017). Digital humanitarians: Citizen journalists on the virtual front line of natural and humancaused disasters. Journalism Practice, 11(2-3), 213-228. https://doi.org/10.1080/17512786.2016. 1228471

Ogania, J. L., Puno, G. R., Alivio, M. B. T., \& Taylaran, J. M. G. (2019). Effect of digital elevation models resolution in producing flood hazard maps. Global Journal of Environmental Science and Management. https://doi.org/10.22034/gjesm.2019.01.08

Our World in Data. (2020). Retrieved 16 July 2020, from https://ourworldindata.org/

Palen, L., Hiltz, S. R., \& Liu, S. B. (2007). Online forums supporting grassroots participation in emergency preparedness and response. Communications of the ACM, 50(3), 54-58. https://doi.org/10.1145/12267 36.1226766

Park, J. Y. (2017). Development of gps based self triage app for disaster vulnerable populations. Journal of Korean Academy of Fundamentals of Nursing, 24(3), 230-242. https://doi.org/10.7739/jkafn.2017. 24.3.230

Pashazadeh, A., \& Javan, M. (2020). Comparison of the gene expression programming, artificial neural network (ANN), and equivalent Muskingum inflow models in the flood routing of multiple branched rivers. Theoretical and Applied Climatology, 139(3), 1349-1362.

Peterson, S., Hughes, A., Stephens, K. K., \& Purohit, H. (2019). When official systems overload: A framework for finding social media calls for help during evacuations. 10.

Reddick, C. (2011). Information technology and emergency management: Preparedness and planning in US states. Disasters, 35(1), 45-61.

References: Regional and World Maps-The World Factbook-Central Intelligence Agency. (2020). Retrieved 16 July 2020, from https://www.cia.gov/library/publications/the-world-factbook/docs/refma ps.html

Regional groupings-SDG Indicators. (2020). Retrieved 16 July 2020, from https://unstats.un.org/sdgs/ report/2019/regional-groups/

Rogstadius, J., Kostakos, V., Laredo, J., \& Vukovic, M. (2011). Towards real-time emergency response using crowd supported analysis of social media.

Roth, S., \& Luczak-Roesch, M. (2020). Deconstructing the data life-cycle in digital humanitarianism. Information, Communication and Society, 23(4), 555-571. https://doi.org/10.1080/1369118X.2018.15214 57

Sausen, T. M., \& Lacruz, M. S. P. (2015). Sensoriamento remoto para desastres. Oficina de Textos.

Segura, A., Olmedo, G., Acosta, F., \& Santillan, M. (2015). Designing a system for monitoring and broadcasting early warning signs of natural disasters for digital terrestrial television. 2015 7th IEEE LatinAmerican Conference on Communications (LATINCOM), 1-6. https://doi.org/10.1109/LATINCOM. 2015.7430119

Shklovski, I., Burke, M., Kiesler, S., \& Kraut, R. (2010). Technology adoption and use in the aftermath of hurricane Katrina in New Orleans. American Behavioral Scientist, 53(8), 1228-1246. https://doi.org/ $10.1177 / 0002764209356252$

Statista database. (2020). Retrieved 16 July 2020, from https://www.statista.com/search/?q=languages\& $\mathrm{qKat}=$ search

Stats, S. G. (2019). Mobile operating system market share worldwide. Dostopno Prek https://Gs. Statcounter. Com/Os-Market-Share/Mobile/Worldwide.

Strzelecki, A. (2019). A Framework for App Store Optimization. ArXiv Preprint http://arxiv.org/abs/1905. 11668. 
Troy, D. A., Carson, A., Vanderbeek, J., \& Hutton, A. (2008). Enhancing community-based disaster preparedness with information technology. Disasters, 32(1), 149-165.

Uitto, J. I., \& Shaw, R. (2016). Sustainable development and disaster risk reduction. Springer.

UN, U. N. . (2015). Sendai framework for disaster risk reduction 2015-2030. United Nations New York.

UNDRR, U. N. O. for D. R. R. (1994). World conference on natural disaster reduction.

UNDRR, U. N. O. for D. R. R. . (2019). Global assessment report on disaster risk reduction 2019. UN Office for Disaster Risk Reduction.

UNESCO Atlas of the World's Languages in danger. (2020). Retrieved 16 July 2020, from http://www.unesco.org/languages-atlas/

van der Aalst, W. M. P., Bichler, M., \& Heinzl, A. (2017). Responsible data science. Business and Information Systems Engineering, 59(5), 311-313. https://doi.org/10.1007/s12599-017-0487-z

Verrucci, E., Perez-Fuentes, G., Rossetto, T., Bisby, L., Haklay, M., Rush, D., Rickles, P., Fagg, G., \& Joffe, H. (2016). Digital engagement methods for earthquake and fire preparedness: A review. Natural Hazards. https://doi.org/10.1007/s11069-016-2378-X

Victor, C. (2014). Diálogo nos cenários de riscos de desastres. KÜnSCH, Dimas; AZEVEDO, Guilherme; BRITO, Pedro; MANSI, Viviane (Orgs.). Comunicação, Diálogo e Compreensão. Plêiade, 179-191.

Wahlstrom, M., \& Guha-Sapir, D. (2015). The human cost of weather-related disasters 1995-2015. Geneva, Switzerland: UNISDR.

Wahyu, Y., Shiddiq, M. S. H., \& Wahab, M. (2012). Design and realization of an early warning system for natural disaster on digital television in Indonesia. 2012 IEEE International Symposium on Broadband Multimedia Systems and Broadcasting (BMSB 2012), 1-4. https://doi.org/10.1109/BMSB.2012.62642 78

Wang, X., Lv, J., Ding, X., \& Dou, A. (2016). Digital disaster evaluation and its application to 2015 Ms 8.1 Nepal earthquake. IOP Conference Series: Earth and Environmental Science, 46, 12056. https://doi. org/10.1088/1755-1315/46/1/012056

Webb, T. L., Joseph, J., Yardley, L., \& Michie, S. (2010). Using the internet to promote health behavior change: A systematic review and meta-analysis of the impact of theoretical basis, use of behavior change techniques, and mode of delivery on efficacy. Journal of Medical Internet Research, 12(1), e4. https://doi.org/10.2196/jmir.1376

WEF, W. E. F. (2020). The Global Risks Report 2020.

Wilkinson, M. D., Dumontier, M., Aalbersberg, Ij., \& J., Appleton, G., Axton, M., Baak, A., Blomberg, N., Boiten, J.-W., da Silva Santos, L. B., \& Bourne, P. E. . (2016). The FAIR Guiding Principles for scientific data management and stewardship. Scientific Data. https://doi.org/10.1038/sdata.2016.18

Williams, L. L., \& Lück-Vogel, M. (2020). Comparative assessment of the gis based bathtub model and an enhanced bathtub model for coastal inundation. Journal of Coastal Conservation, 24(2), 23. https:// doi.org/10.1007/s11852-020-00735-x

World Bank \& United Nations. (2010). Natural hazards, unnatural disasters: The economics of effective prevention. The World Bank.

World Bank Open DatalData. (2020). Retrieved 16 July 2020, from https://data.worldbank.org/

Worlddata: The world in numbers. (2020). Retrieved 16 July 2020, from https://www.worlddata.info/

Xu, X., Zhang, L., Sotiriadis, S., Asimakopoulou, E., Li, M., \& Bessis, N. (2018). CLOTHO: A large-scale internet of things-based crowd evacuation planning system for disaster management. IEEE Internet of Things Journal, 5(5), 3559-3568. https://doi.org/10.1109/JIOT.2018.2818885

Yu, M., Bambacus, M., Cervone, G., Clarke, K., Duffy, D., Huang, Q., Li, J., Li, W., Li, Z., Liu, Q., Resch, B., Yang, J., \& Yang, C. (2020). Spatiotemporal event detection: A review. International Journal of Digital Earth. https://doi.org/10.1080/17538947.2020.1738569

Publisher's Note Springer Nature remains neutral with regard to jurisdictional claims in published maps and institutional affiliations. 